\title{
Nanoscale
}

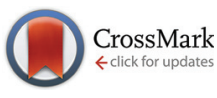

Cite this: Nanoscale, 2015, 7, 2597

Received 11th September 2014 Accepted 22nd November 2014

DOI: $10.1039 / \mathrm{c} 4 \mathrm{nr} 05165 \mathrm{c}$

www.rsc.org/nanoscale

\section{Tuning the reorganization energy of electron transfer in supramolecular ensembles - metalloporphyrin, oligophenylenevinylenes, and fullerene - and the impact on electron transfer kinetics $\uparrow$}

\author{
Christina Stangel, $\neq^{\mathrm{a}}$ Christina Schubert, $t^{\mathrm{b}}$ Susanne Kuhri, ${ }^{\mathrm{b}}$ Georgios Rotas, ${ }^{\mathrm{c}}$ \\ Johannes T. Margraf, ${ }^{\text {b,d }}$ Elzbieta Regulska, ${ }^{e}$ Timothy Clark, ${ }^{* d}$ Tomás Torres, ${ }^{f, g}$ \\ Nikos Tagmatarchis, ${ }^{\star c}$ Athanassios G. Coutsolelos ${ }^{\star a}$ and Dirk M. Guldi*b
}

\begin{abstract}
Oligo(p-phenylenevinylene) (oPPV) wires of various lengths featuring pyridyls at one terminal and $\mathrm{C}_{60}$ moieties at the other, have been used as molecular building blocks in combination with porphyrins to construct a novel class of electron donor-acceptor architectures. These architectures, which are based on non-covalent, directional interactions between the zinc centers of the porphyrins and the pyridyls, have been characterized by nuclear magnetic resonance spectroscopy and mass spectrometry. Complementary physico-chemical assays focused on the interactions between electron donors and acceptors in the ground and excited states. No appreciable electron interactions were noted in the ground state, which was being probed by electrochemistry, absorption spectroscopy, etc.; the electron acceptors are sufficiently decoupled from the electron donors. In the excited state, a different picture evolved. In particular, steady-state and time-resolved fluorescence and transient absorption measurements revealed substantial electron donor-acceptor interactions. These led, upon photoexcitation of the porphyrins, to tunable intramolecular electron-transfer processes, that is, the oxidation of porphyrin and the reduction of $\mathrm{C}_{60}$. In this regard, the largest impact stems from a rather strong distance dependence of the total reorganization energy in stark contrast to the distance independence seen for covalently linked conjugates.
\end{abstract}

\section{Introduction}

Natural processes of photosynthesis have increasingly inspired the fabrication of nanostructured molecular materials with advanced light-harvesting and electron-transfer features. ${ }^{1-6}$ In

\footnotetext{
${ }^{a}$ Department of Chemistry, University of Crete, Laboratory of Bioinorganic Chemistry, Voutes Campus, P.O. Box 2208, 71003 Heraklion, Crete, Greece.

E-mail: coutsole@chemistry.uoc.gr

${ }^{b}$ Department of Chemistry and Pharmacy, Interdisciplinary Center for Molecular Materials (ICMM), Friedrich-Alexander-Universität Erlangen-Nuernberg, Egerlandstr. 3, 91058 Erlangen, Germany. E-mail: dirk.guldi@fau.de

${ }^{c}$ Theoretical and Physical Chemistry Institute, National Hellenic Research Foundation, 48 Vassileos Constantinou Avenue, Athens 11635, Greece. E-mail: tagmatar@eie.gr

${ }^{d}$ Computer Chemie Centrum, Department of Chemistry and Pharmacy, Friedrich-Alexander-Universitaet Erlangen-Nuernberg, Naegelsbachstraße 25, 91052 Erlangen, Germany. E-mail: tim.clark@fau.de

${ }^{e}$ Institute of Chemistry, University of Bialystok, Hurtowa 1, 15-399 Bialystok, Poland

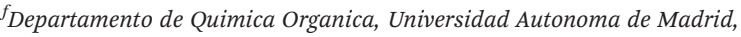
Cantoblanco, 28049-Madrid, Spain

${ }^{g}$ IMDEA-Nanociencia, C/Faraday, 9, Cantoblanco, 28049-Madrid, Spain

$\dagger$ Electronic supplementary information (ESI) available. See DOI: 10.1039/c4nr05165c

$\$$ These authors contributed equally to this work.
}

this context, supramolecular chemistry allows diverse and disparate molecular building blocks to be amalgamated into highly ordered architectures. These mimic the key functions of the photosynthetic reaction center: light harvesting, charge separation, charge transport, and catalysis. ${ }^{7-10}$ Porphyrinoids, the basic building block of chlorophylls, have emerged as an exceptional class of light harvesters and electron donors in such supramolecular electron donor-acceptor hybrids. This is mainly because porphyrinoids absorb a large fraction of the visible light (with extinction coefficient as high as $10^{5} \mathrm{M}^{-1}$ $\mathrm{cm}^{-1}$ ) and because they give rise to a remarkable redox chemistry. ${ }^{11,12}$ As a complement to porphyrinoids, fullerenes, in general, and $\mathrm{C}_{60}$, in particular, have unique physico-chemical properties that render them versatile electron acceptors in their ground state. Their three-dimensional structure, low reduction potentials, and small reorganization energy in electron transfer processes ${ }^{13,14}$ are most notable in this context. Among others, these are important prerequisites for powering the unidirectional electron-transfer processes and controlling the corresponding efficiencies and rates. ${ }^{15,16}$

The conjugated nature of oPPVs also provides some structural rigidity between their termini. For example, only 
rotational motions about the formal single bonds are thermally accessible at room temperature. Thus, the incorporation of rigid oPPVs into electron donor-acceptor architectures is an essential tool for fixing the spatial separation of electron donors and acceptors at the opposing termini. The oPPVs also play a mediating role in charge-separation and recombination processes without, however, actively participating in the electron transport at room temperature. ${ }^{17,18}$ Their electron donor and acceptor levels, on the one hand, and those of the electron donors and acceptors, on the other, are decisive in favoring a coherent tunneling mechanism. For example, the electron acceptor levels of the oPPVs should be higher than those of the light harvester/electron donor and of the electron acceptor.

In the context of oPPVs and $\mathrm{C}_{60}$, molecular architectures that give rise to consecutive energy- and electron-transfer processes to $\mathrm{C}_{60}$ upon photoexcitation have been constructed using fullerene-based dendritic structures and oPPVs. ${ }^{19-24}$ As a further elaboration, electron donors, such as ferrocene etc. have been attached covalently to $\mathrm{C}_{60}$-oPPVs and the resulting conjugates have been probed by means of photophysical and electrochemical techniques. $^{25}$

More recently, investigations have focused on advanced electron donor-acceptor conjugates. Most notably, oPPV conjugates carrying $\mathrm{C}_{60}$ as the electron acceptor and either metalloporphyrins $(\mathrm{ZnP})$ or $\pi$-extended tetrathiafulvalenes (exTTF) as electron donors have been designed and tested with particular focus on their physico-chemical properties. ${ }^{17,18,26,27}$ Long-lived charge-separated states were identified in $\mathrm{C}_{60}$-oPPV-ZnPs as products of the rapid deactivation of the $\mathrm{ZnP}$ singlet excited state. $^{28,29}$ In $\mathrm{C}_{60}$-oPPV-ZnPs, the electron-transfer rates for fast charge separation and slow charge recombination are close to the top and inverted region of the Marcus parabola, respectively. A key factor for such a parabolic Marcus relationship is the total reorganization energy, which stems from both the electron donors and the electron acceptors. ${ }^{30,31}$ This is small in $\mathrm{C}_{60}$-oPPV-ZnPs because of the formation of highly delocalized $\mathrm{ZnP}$ radical cations and $\mathrm{C}_{60}$ radical anions. Linking the oPPVs to the phenyls of ZnP also provides a beneficial contribution to keep the total reorganization energy small.

A plethora of $\mathrm{C}_{60}-\mathrm{oPPV}$ conjugates has been reported, including examples in which the length and the number of oPPVs were altered systematically in order to establish the relationship between electron-transfer rates and electron donor-acceptor distances. ${ }^{29,32-37}$ Attenuation factors as small as $0.01 \AA^{-1}$ were derived from the measured distance dependences of electron transfer for both charge separation and recombination processes. The reorganization energies for electron transfer in these $\mathrm{C}_{60}$-oPPVs and, more importantly, their distance dependence have never been investigated in detail. Nevertheless, these studies gave no indication of a change in the outcome of the excited-state deactivation or in the associated kinetics.

Self-assembling of the discrete molecular building blocks in a specific and well-ordered way en route to architectures with precise functions such as photoinduced charge transfer phenomena, ${ }^{38-40}$ constitutes an intriguing aspect of supra- molecular chemistry. ${ }^{41,42}$ To the best of our knowledge, supramolecular assemblies of light-harvesting/electron-donating porphyrins and oPPVs of different lengths in the presence of electron accepting $\mathrm{C}_{60}$ have never been carried out. Thus, it is timely and necessary to assemble such architectures and to test their efficiencies in terms of charge-transfer events.

Our aim in this work has been to approach a number of objectives systematically. Firstly, to functionalize $\mathrm{C}_{60}$ with a series of oPPVs of different lengths and carrying pyridyl moieties - $\mathbf{C}_{\mathbf{6 0}}$-oPPV-pyr. The pyridyls in $\mathbf{C}_{\mathbf{6 0}}$-oPPV-pyrs are essential as anchors to coordinate $\mathrm{ZnP}$ and to enable the formation of novel electron donor/acceptor architectures $-\mathbf{C}_{\mathbf{6 0}}-\mathbf{- O P P V}-\mathbf{p y r}$ ZnP. Secondly, to characterize in detail the newly formed $\mathbf{C}_{60}$-oPPV-pyr-ZnPs by, for example, nuclear magnetic resonance spectroscopy, mass spectrometry, electrochemistry, etc. Thirdly, to explore the basic electron-transfer phenomenon in the novel electron donor acceptor $\mathbf{C}_{\mathbf{6 0}}$-oPPV-pyr-ZnPs by steadystate and time-resolved photophysical techniques. Finally, to determine whether the oPPV length plays a key role in the formation of charge-separated states.

\section{Experimental section}

\section{General methods}

Reagents and solvents of reagent grade were purchased and used without further purification. All solvents were dried by the appropriate techniques. ${ }^{43} \mathbf{Z n P}^{44}$ was prepared according to a previously reported procedure. Thin layer chromatography was performed on silica gel $60 \mathrm{~F}_{254}$ plates. Chromatography was carried out on $\mathrm{SiO}_{2}$ (silica gel 60, SDS, 70-230 mesh ASTM). HPLC separations were performed on an LC-9101 instrument using a CosmosilBuckyprep $20 \times 250 \mathrm{~mm}$ preparative column and toluene as the mobile phase at $10 \mathrm{~mL} \mathrm{~min}^{-1}$.

4-[(Bromotriphenylphosphoranyl)methyl]pyridine (2). Salt 1 (0.500 $\mathrm{mg}, 1.98 \mathrm{mmol}$ ) and $\mathrm{Na}_{2} \mathrm{CO}_{3}(0.21 \mathrm{~g}, 1.98 \mathrm{mmol})$ were dissolved in $2 \mathrm{~mL}$ of water and then the obtained solution was extracted with diethyl ether $(50 \mathrm{~mL})$ until the desired 4-(bromomethyl) pyridine was obtained. To the combined extracts, toluene $(20 \mathrm{~mL})$ was added, and the mixture was distilled until all of the diethyl ether had evaporated. Then triphenylphosphine $(0.754 \mathrm{~g}, 2.88 \mathrm{mmol})$ was added and the mixture was heated at reflux for $3 \mathrm{~h}$. The white precipitate was filtered, washed with toluene and subsequently dried under vacuum. This afforded the monophosphonium salt 2 as a white solid $(0.380 \mathrm{~g}, 44.3 \%) .{ }^{1} \mathrm{H} \mathrm{NMR}\left(500 \mathrm{MHz}, \mathrm{CDCl}_{3}\right): \delta 8.30(\mathrm{sb}, 2 \mathrm{H})$, $7.85-7.80(\mathrm{~m}, 6 \mathrm{H}), 7.76(\mathrm{~m}, 3 \mathrm{H}), 7.60-7.57(\mathrm{~m}, 6 \mathrm{H}), 7.23(\mathrm{sb}$, $2 \mathrm{H}), 5.80$ (d, $J=16 \mathrm{~Hz}, 2 \mathrm{H}) .{ }^{13} \mathrm{C} \mathrm{NMR}\left(125 \mathrm{MHz}, \mathrm{CDCl}_{3}\right): 149.7$, 138.1, 135.2, 134.5, 130.3, 126.9, 177.5, 29.7. HRMS (MALDITOF): $m / z$ calcd for $\mathrm{C}_{24} \mathrm{H}_{21} \mathrm{BrNP}: 433.0595[\mathrm{M}]^{+}$. Found: 433.0601 .

4-\{(E)-4-[(E)-2,5-Bis(dodecyloxy)-4-((E)-2-(pyridin-4-yl)vinyl)styryl]-2,5-bis(dodecyloxy)styryl\}-2,5-bis(dodecyloxy)benzaldehyde $(\boldsymbol{E}-5)$. To a solution of $3(0.20 \mathrm{~g}, 0.138 \mathrm{mmol})$ and $2(0.060 \mathrm{~g}$, $0.138 \mathrm{mmol})$ in dry methylene chloride $(100 \mathrm{~mL})$ lithium ethoxide solution $(0.360 \mathrm{~mL}, 1.0 \mathrm{M}$ in ethanol) was added 
dropwise at room temperature. The resulting solution was stirred for 20 min more after the completion of base addition. The reaction was quenched by the addition of dilute aqueous $\mathrm{HCl}$. The organic layer was separated, washed with water, dried $\left(\mathrm{Na}_{2} \mathrm{SO}_{4}\right)$, filtered and concentrated. In the resulting residue traces of the $Z$ isomer were observed in a $97: 3$ ratio. Column chromatography $\left(\mathrm{SiO}_{2}, \mathrm{CH}_{2} \mathrm{Cl}_{2}-\mathrm{EtOH}, 100: 0.5\right)$ gave $E-5(0.13 \mathrm{~g}, 61.8 \%)$ as an orange fluorescent solid. ${ }^{1} \mathrm{H}$ NMR $\left(300 \mathrm{MHz}, \mathrm{CDCl}_{3}\right): \delta$ 0.87-0.88 (m, 18H), $1.34(\mathrm{~m}, 96 \mathrm{H}), 1.53$ $(\mathrm{m}, 12 \mathrm{H}), 1.87(\mathrm{~m}, 12 \mathrm{H}), 4.06(\mathrm{~m}, 12 \mathrm{H}), 7.07(\mathrm{AB}, J=16 \mathrm{~Hz}$, $1 \mathrm{H}), 7.11(\mathrm{~s}, 1 \mathrm{H}), 7.15(\mathrm{~s}, 1 \mathrm{H}), 7.16(\mathrm{~s}, 1 \mathrm{H}), 7.18(\mathrm{~s}, 1 \mathrm{H}), 7.21$ (s, 1H), $7.33(\mathrm{~s}, 1 \mathrm{H}), 7.44(\mathrm{~d}, J=5 \mathrm{~Hz}, 2 \mathrm{H}), 7.51(\mathrm{~m}, 3 \mathrm{H}), 7.60$ $(\mathrm{AB}, J=16.5 \mathrm{~Hz}, 1 \mathrm{H}), 7.72(\mathrm{AB}, J=16.5 \mathrm{~Hz}, 1 \mathrm{H}), 8.57(\mathrm{sb}, 2 \mathrm{H})$, 10.45 (s, 1H). ${ }^{13} \mathrm{C}$ NMR (125 MHz, $\left.\mathrm{CDCl}_{3}\right): 189.3,156.4,151.9$, $151.6,151.3,151.1,150.8,149.1,146.6,135.3$, 129.4, 129.2, $128.2,127.2,126.1,125.5,125.2$, 124.5, 124.2, 123.7, 123.0, $121.1,111.3,111.0,110.7,110.5,110.3$, 69.5, 32.0, 29.4, 26.4, 22.8, 14.2. HRMS (MALDI-TOF): $\mathrm{m} / z$ calcd for $\mathrm{C}_{102} \mathrm{H}_{167} \mathrm{NO}_{7}$ : 1518.2743 [M] $]^{+}$. Found: 1518.2735 .

(E)-2,5-Bis(dodecyloxy)-4-[2-(pyridin-4-yl)vinyl]benzaldehyde $(\boldsymbol{E}-6)$. To a solution of $4(0.19 \mathrm{~g}, 0.380 \mathrm{mmol})$ and $2(0.166 \mathrm{~g}$, $0.380 \mathrm{mmol})$ in dry methylene chloride $(25 \mathrm{~mL})$ lithium ethoxide solution ( $1 \mathrm{~mL}, 1.0 \mathrm{M}$ in ethanol) was added dropwise at room temperature. The resulting solution was stirred for 20 min more after the completion of base addition. The reaction was quenched by the addition of dilute aqueous $\mathrm{HCl}$. The organic layer was separated, washed with water, dried $\left(\mathrm{Na}_{2} \mathrm{SO}_{4}\right)$, filtered and concentrated. Column chromatography $\left(\mathrm{SiO}_{2}, \mathrm{CH}_{2} \mathrm{Cl}_{2}-\mathrm{EtOH}, 100: 0.1\right)$ gave 6 as an $E: Z$ isomer mixture in a 90:10 ratio. A second column chromatography $\left(\mathrm{SiO}_{2}\right.$, toluene-EtOAc, $\left.100: 5\right)$ gave $E-6$ in pure form $(0.144 \mathrm{~g}$, $66 \%$ ) as a yellow fluorescent solid. ${ }^{1} \mathrm{H} \mathrm{NMR}\left(500 \mathrm{MHz}, \mathrm{CDCl}_{3}\right)$ : $\delta 0.87(\mathrm{~m}, 6 \mathrm{H}), 1.30(\mathrm{~m}, 32 \mathrm{H}), 1.49(\mathrm{~m}, 4 \mathrm{H}), 1.85(\mathrm{~m}, 4 \mathrm{H}), 4.04$ $(\mathrm{t}, J=6.5 \mathrm{~Hz}, 2 \mathrm{H}), 4.10(\mathrm{t}, J=6.5 \mathrm{~Hz}, 2 \mathrm{H}), 7.16(\mathrm{~s}, 1 \mathrm{H}), 7.17(\mathrm{AB}$, $J=16.5 \mathrm{~Hz}, 1 \mathrm{H}), 7.34(\mathrm{~s}, 1 \mathrm{H}), 7.39(\mathrm{~d}, J=6 \mathrm{~Hz}, 2 \mathrm{H}), 7.65(\mathrm{AB}$, $J=16.5 \mathrm{~Hz}, 1 \mathrm{H}), 8.60(\mathrm{~d}, J=6 \mathrm{~Hz}, 2 \mathrm{H}), 10.46(\mathrm{~s}, 1 \mathrm{H}) .{ }^{13} \mathrm{C} \mathrm{NMR}$ $\left(125 \mathrm{MHz}, \mathrm{CDCl}_{3}\right): \delta 189.3,156.1,150.3,151.2,144.7,132.8$, $129.5,127.8,125.3,123.5,121.2$, 111.4, 110.4, 69.3, 32.0, 29.8, 29.7, 29.7, 29.7, 29.5, 29.5, 29.4, 29.3, 26.3, 26.2, 22.8, 14.2. HRMS (MALDI-TOF): $\mathrm{m} / z$ calcd for $\mathrm{C}_{38} \mathrm{H}_{59} \mathrm{NO}_{3}: 577.4495[\mathrm{M}]^{+}$. Found: 577.4502 .

C $_{60}$-PPV3-pyr. A mixture of $E-5(0.084 \mathrm{~g}, 0.055 \mathrm{mmol}), \mathrm{C}_{60}$ $(0.040 \mathrm{~g}, 0.055 \mathrm{mmol})$ and sarcosine $(0.049 \mathrm{~g}, 0.55 \mathrm{mmol})$ in toluene $(40 \mathrm{~mL})$ was refluxed for $4 \mathrm{~h}$. After cooling, the reaction mixture was transferred onto the top of a silica gel column and eluted with toluene to collect the unreacted $\mathrm{C}_{60}(10 \mathrm{mg}, 25 \%)$. Then further elusion with a mixture of toluene and ethylacetate $(100: 5)$ gave the impure product which was purified by preparative HPLC (retention time $=10 \mathrm{~min}$ ) resulting in $\mathbf{C}_{60}$-PPV3-pyr $(0.052 \mathrm{~g}, 41 \%)$ as a sticky brown-orange solid. ${ }^{1} \mathrm{H}$ NMR (500 MHz, $\left.\mathrm{CDCl}_{3}\right): \delta 0.88$ (m, 18H), 1.25-1.54 (m, 108H), 1.78-1.87 (m, 12H), $2.84(\mathrm{~s}, 3 \mathrm{H}), 3.77(\mathrm{~m}, 1 \mathrm{H}), 4.06$ $(\mathrm{m}, 11 \mathrm{H}), 4.32(\mathrm{~d}, J=9.5 \mathrm{~Hz}, 1 \mathrm{H}), 4.98(\mathrm{~d}, J=9 \mathrm{~Hz} 1 \mathrm{H}), 5.56$ (s, 1H), $7.05(\mathrm{AB}, J=16.5 \mathrm{~Hz}, 1 \mathrm{H}), 7.10-7.16(\mathrm{~m}, 5 \mathrm{H}), 7.40$ $(\mathrm{sb}, 2 \mathrm{H}), 7.50(\mathrm{~m} 4 \mathrm{H}), 7.60(\mathrm{~s}, 1 \mathrm{H}), 7.69(\mathrm{AB}, J=16.5 \mathrm{~Hz}, 1 \mathrm{H})$, 8.57 (sb, 2H). ${ }^{13} \mathrm{C} \mathrm{NMR}\left(75 \mathrm{MHz}, \mathrm{CDCl}_{3}\right): \delta 156.9,155.3,154.6$,
$154.0,152.2,151.8,151.2,151.0,149.8,147.4,146.9,146.2$, $146.1,145.9,145.7,145.4,145.3,144.7,144.5,143.2,142.8$, $142.7,142.3,142.1,141.9,140.3,139.9,139.6,136.6,136.4$, $136.3,134.7,129.4,128.7,127.8,127.7,127.3,125.6,125.1$, $124.5,124.0,123.7,123.2,121.0,115.0,111.3,110.8,110.7$, 110.5, 109.6, 75.9, 69.1, 69.7, 69.6, 68.7, 40.3, 32.07, 31.4, 29.7, 26.4, 22.8, 14.3. IR: $\tilde{\nu} 2919.77,2849.80,1591.55,1462.94$, 1420.50, 1030.55, 967.12, 850.59, 719.90, $526.47 \mathrm{~cm}^{-1}$. HRMS (MALDI-TOF): $m / z$ calcd for $\mathrm{C}_{164} \mathrm{H}_{173} \mathrm{~N}_{2} \mathrm{O}_{6}: 2266.3294[\mathrm{M}+\mathrm{H}]^{+}$. Found: 2266.3288.

C $_{60}$-PPV1-pyr. A mixture of E-6 (0.044 g, $\left.0.076 \mathrm{mmol}\right), \mathrm{C}_{60}$ $(0.055 \mathrm{~g}, 0.076 \mathrm{mmol})$ and sarcosine $(0.068 \mathrm{~g}, 0.76 \mathrm{mmol})$ in toluene $(40 \mathrm{~mL})$ was refluxed for $3 \mathrm{~h}$. After cooling, the reaction mixture was transferred onto the top of a silica gel column and eluted with toluene to collect the unreacted $\mathrm{C}_{60}(12.4 \mathrm{mg}$, $22.6 \%)$. Then further elusion with a mixture of toluene and ethylacetate $(100: 5)$ gave the impure product which was purified by preparative HPLC (retention time $=17 \mathrm{~min}$ ) resulting in C $60_{\text {-PPV1-pyr }}$ (0.043 g, 42.3\%) as a sticky brown-orange solid. ${ }^{1} \mathrm{H}$ NMR (300 MHz, $\left.\mathrm{CDCl}_{3}\right): \delta 0.87(\mathrm{~m}, 6 \mathrm{H}), 1.25(\mathrm{~m}, 32 \mathrm{H})$, 1.62-1.69 (m, 4H), $1.80(\mathrm{~m}, 4 \mathrm{H}), 2.83(\mathrm{~s}, 3 \mathrm{H}), 3.75(\mathrm{~m}, 1 \mathrm{H}), 4.04$ $(\mathrm{m}, 2 \mathrm{H}), 4.15(\mathrm{~m}, 1 \mathrm{H}), 4.32(\mathrm{~d}, J=9.6 \mathrm{~Hz}, 1 \mathrm{H}), 4.98(\mathrm{~d}, J=$ $9.3 \mathrm{~Hz}, 1 \mathrm{H}), 5.56(\mathrm{~s}, 1 \mathrm{H}), 7.05(\mathrm{AB}, J=16.5 \mathrm{~Hz}, 1 \mathrm{H}), 7.10$ $(\mathrm{s}, 1 \mathrm{H}), 7.36(\mathrm{~m}, 2 \mathrm{H}), 7.60(\mathrm{~s}, 1 \mathrm{H}), 7.66(\mathrm{AB}, J=16.5 \mathrm{~Hz}, 1 \mathrm{H})$, $8.56(\mathrm{sb}, 2 \mathrm{H}) .{ }^{13} \mathrm{C} \mathrm{NMR}\left(75 \mathrm{MHz}, \mathrm{CDCl}_{3}\right): \delta 156.8,155.1,154.3$, $152.1,151.6,149.8,147.5,147.4,146.9,146.8,146.4,146.3$, 146.2 , 146.1, 145.9, 145.8, 145.7, 145.6, 145.5, 145.4, 145.3, $144.7,144.6,144.5,143.2,142.8,142.7,143.2,143.1,142.8$, $142.7,142.5,142.4,142.3,142.2,142.1,141.9,141.9,140.3$, $139.8,139.6,136.4,136.2,134.8,128.7,127.6,126.4$, 125.7121.0, 115.0, 110.2, 70.0, 69.9, 69.4, 68.9, 40.3, 32.0, 29.6, 29.5, 29.4, 29.8, 14.3. IR: $\tilde{\nu} 2916.40,2847.64,1590.48,1461.17$, 1461.17, 1413.32, 1258.07, 1010.84, 792.55, $524.73 \mathrm{~cm}^{-1}$. HRMS (MALDI-TOF): $m / z$ calcd for $\mathrm{C}_{100} \mathrm{H}_{64} \mathrm{~N}_{2} \mathrm{O}_{2}: 1324.4968[\mathrm{M}]^{+}$. Found: 1324.4979.

\section{NMR spectroscopy}

${ }^{1} \mathrm{H}$ NMR and ${ }^{13} \mathrm{C}$ NMR spectra were recorded on Bruker AMX-500 MHz and Bruker DPX-300 MHz spectrometers, respectively, as solutions in deuterated solvents by using the solvent peak as the internal standard.

\section{Mass spectrometry}

High-resolution mass spectra were performed on a Bruker ultrafleXtreme MALDI-TOF/TOF spectrometer using trans-2[3-(4-tert-butylphenyl)-2-methyl-2-propenylidene] malononitrile as the matrix.

\section{FTIR spectroscopy}

(ATR)-FTIR spectra were recorded on a Thermo-Electron Nicolet 6700 FTIR optical spectrometer with a DTGS KBr detector at a resolution of $4 \mathrm{~cm}^{-1}$.

\section{Electrochemistry}

Electrochemical data were obtained by cyclic voltammetry using a conventional single-compartment three-electrode cell 
arrangement in combination with a potentiostat "AUTOLAB ${ }^{\circledR}$, eco chemie". As the auxiliary and reference electrodes, Pt and $\mathrm{Ag}$ wires were used, respectively, while the working electrode was a glassy carbon electrode. Tetrabutylammonium hexafluorophosphate $\left(\mathrm{TBAPF}_{6}=0.05 \mathrm{M}\right)$ was used as a supporting electrolyte at room temperature. All potentials are referenced to ferrocene/ferrocenium.

\section{UV/vis absorption spectroscopy}

Steady state absorption spectra were obtained using a Perkin Elmer Lambda 2 UV/vis two-beam spectrophotometer with a slit width of $2 \mathrm{~nm}$ and a scan rate of $480 \mathrm{~nm} \mathrm{~min}{ }^{-1}$. A quartz glass cuvette of $10 \times 10 \mathrm{~mm}$ was used.

\section{Emission spectroscopy}

Steady state emission was recorded using a Horiba Jobin Yvon FluoroMax-3 spectrometer with a slit width of $2 \mathrm{~nm}$ for excitation and emission and an integration time of $0.2 \mathrm{~s}$. A quartz glass cuvette of $10 \times 10 \mathrm{~mm}$ was used. All spectra were corrected for the instrument response. For excitation wavelength below $450 \mathrm{~nm}$ a cut off filter $(435 \mathrm{~nm})$ was inserted.

\section{Fs-transient absorption spectroscopy}

Femtosecond transient absorption studies were performed with laser pulses ( $1 \mathrm{kHz}, 150 \mathrm{fs}$ pulse width) by using an amplified Ti/sapphire laser system (Model CPA 2110, Clark-MXR Inc.; output $775 \mathrm{~nm}$ ). For an excitation wavelength of 420 and $550 \mathrm{~nm}$, a nonlinear optical parametric converter (NOPA) was used to generate ultra-short tunable visible pulses out of the pump pulses. The transient absorption pump probe spectrometer (TAPPS) is a two-beam setup, in which the pump pulse is used as the excitation source for transient species and the delay of the probe pulse is exactly controlled by an optical delay rail. As the probe (white-light continuum), a small fraction of pulses stemming from the CPA laser system were focused by a $50 \mathrm{~mm}$ lens into a $2 \mathrm{~mm}$ thick sapphire disc. The transient spectra were recorded using fresh argon-saturated solutions in each laser excitation. All experiments were performed at $298 \mathrm{~K}$ in a $2 \mathrm{~mm}$ quartz cuvette.

\section{Molecular modeling}

Geometries and local properties were calculated using the semi-empirical AM1 Hamiltonian as implemented in EMPIRE' 12. ${ }^{45-47}$ Local electron affinity ${ }^{48,49}$ was calculated from the resulting molecular orbitals.

\section{Results and discussion}

\section{Synthesis}

The strategy employed for synthesizing $\mathrm{C}_{60}$ functionalized with oPPVs is based on the 1,3-dipolar cycloaddition of azomethine ylides, generated in situ upon the thermal condensation of custom-synthesized oPPV-based aldehydes and sarcosine, to $\mathrm{C}_{60}{ }^{50}$ The synthetic approach to oPPV-based aldehydes relies on Wittig-type reactions. ${ }^{51}$ Scheme 1 illustrates the synthesis

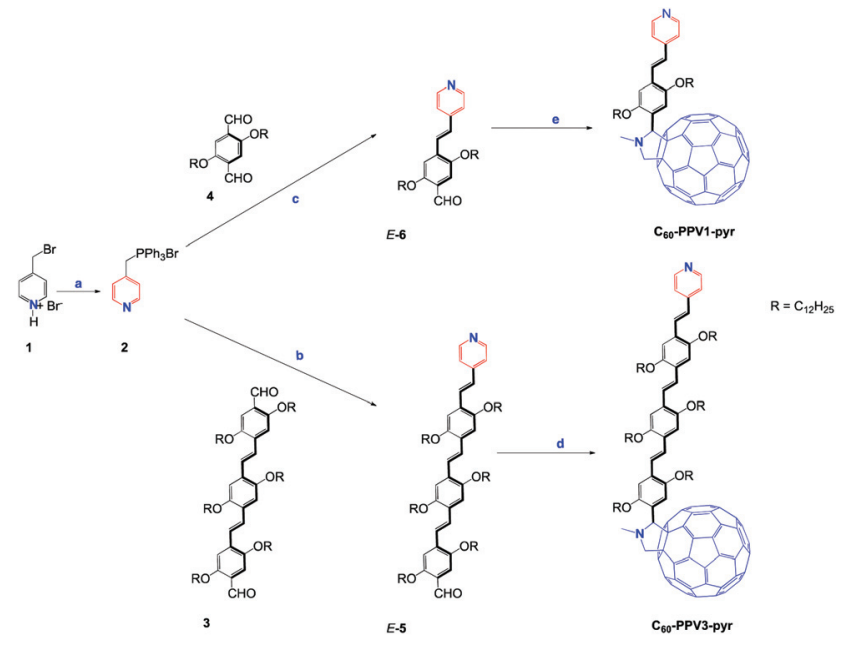

Scheme 1 Synthesis of $\mathrm{C}_{60}-\mathrm{PPV} 1-$ pyr and $\mathrm{C}_{60}-\mathrm{PPV} 3$-pyr. Reagents and conditions: (a) (i) $\mathrm{Na}_{2} \mathrm{CO}_{3}$ (aq.)/ $/ \mathrm{Et}_{2} \mathrm{O}$, (ii) $\mathrm{PPh}_{3}$, toluene, reflux, $3 \mathrm{~h}, 44 \%$; (b) 3, LiOEt, $\mathrm{CH}_{2} \mathrm{Cl}_{2}$, room temperature, $20 \mathrm{~min}, 62 \%$; (c) 4, LiOEt, $\mathrm{CH}_{2} \mathrm{Cl}_{2}$, room temperature, 20 min, $66 \%$; (d) $E-5, \mathrm{C}_{60}$, sarcosine, toluene, reflux, $4 \mathrm{~h}, 41 \%$; (e) $E-6, C_{60}$, sarcosine, toluene, reflux, $3 \mathrm{~h}$, $42 \%$.

of two oPPV-based aldehydes of different lengths $E-\mathbf{5}$ and $E-\mathbf{6}$, both terminated with a pyridyl group, and the preparation of the corresponding $\mathbf{C}_{60}$-PPV3-pyr and $\mathbf{C}_{60}$-PPV1-pyr. Briefly, 2,5bis(dodecyloxy)benzene-1,4-dialdehyde 4 was prepared in three steps from hydroquinone in $45 \%$ yield according to a modified method (see ESI† for details). ${ }^{52,53}$ Bis-aldehyde 3 was prepared in $81 \%$ yield from hydroquinone in five steps using a Wittigreaction and was also prepared in seven steps using the Horner-Wadsworth-Emmons (HWE) reaction (see ESI $\dagger$ for details). Then, the Wittig reaction of 3 in the presence of LiOEt with the pyridylphosphonium salt 2 , which was made from $\mathbf{1}$, afforded the $E$-isomer of oPPV-based aldehyde $E$-5, along with traces $(3 \%)$ of the $Z$-isomer. Column chromatography gave $E$-isomer 5 in pure form in $62 \%$ yield. Under a similar Wittig reaction, 4 gave access to the $E$-isomer of oPPV-based aldehyde $E-6$ (66\% yield). Thus, with oPPV-based aldehydes $E-5$ and $E-6$ in hand, $\mathbf{C}_{60}$-PPV3-pyr and $\mathbf{C}_{60}$-PPV1-pyr were obtained on 1,3dipolar cycloaddition in the presence of sarcosine. At this stage, it should be noted that $\mathbf{C}_{60}$-PPV1-pyr and $\mathbf{C}_{60}$-PPV3-pyr were purified by recycling HPLC (Buckyprep Cosmosil column,

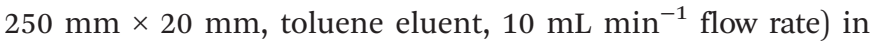
$42 \%$ and $41 \%$, respectively. The dodecyloxy groups as side chains of the $\mathbf{C}_{60}$-PPV1-pyr and $\mathbf{C}_{60}$-PPV3-pyr provide enhanced solubility in common organic solvents such as toluene, dichloromethane, THF, etc. and thus allow for a complete spectroscopic characterization (Scheme 2).

In brief, the characteristic ${ }^{1} \mathrm{H}$ NMR pattern for the $E$-configuration of the vinylic protons in oPPVs includes a rather large coupling constant $(16.5 \mathrm{~Hz})$ for the corresponding $\mathrm{AB}$ system in $\mathbf{C}_{\mathbf{6 0}}$-PPV1-pyr and $\mathbf{C}_{\mathbf{6 0}}$-PPV3-pyr. Furthermore, their structures were confirmed by identifying their molecular ion peaks in the MALDI-TOF mass spectra; $\left[\mathrm{M}^{+}\right] 1324.4979$ for $\mathbf{C}_{60}$-PPV1-pyr and $\left[\mathrm{M}^{+}\right] 2266.3288$ for $\mathbf{C}_{60}$-PPV3-pyr. 


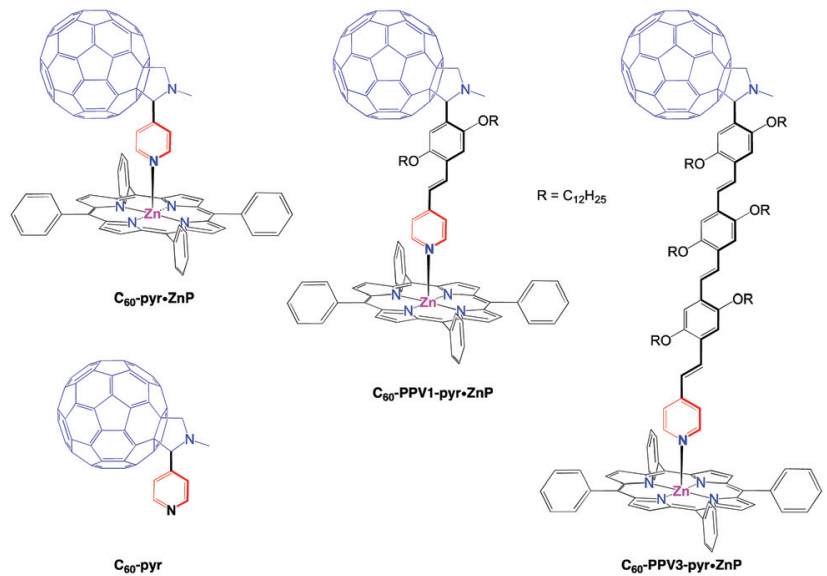

Scheme 2 Hybrids $\mathrm{C}_{60}$-pyr-ZnP, C60-PPV1-pyr-ZnP, C60-PPV3-pyr-ZnP and reference $\mathrm{C}_{60}$-pyr.

Table 1 Electrochemical data ${ }^{a}$

\begin{tabular}{|c|c|c|c|}
\hline Compound & $E_{\mathrm{OX}}^{1}$ & $E_{\text {red }}^{1}$ & $E_{\text {red }}^{2}$ \\
\hline $\mathrm{ZnP}$ & 0.33 & & \\
\hline $\mathrm{C}_{60}-\mathrm{pyr}$ & & -1.24 & -1.63 \\
\hline $\mathrm{C}_{60}-\mathrm{PPV} 1$ & & -1.24 & -1.65 \\
\hline $\mathrm{C}_{60}-\mathrm{PPV} 3$ & & -1.24 & -1.65 \\
\hline $\mathrm{C}_{60}$-pyr-ZnP & 0.31 & -1.21 & \\
\hline $\mathrm{C}_{60}$-PPV1.ZnP & 0.32 & -1.25 & \\
\hline $\mathrm{C}_{60}-\mathrm{PPV} 3 \cdot \mathrm{ZnP}$ & 0.32 & -1.25 & \\
\hline
\end{tabular}

${ }^{a}$ Potentials in $\mathrm{V}$ (half-wave potentials: $E_{1 / 2}$ ); scan rate $100 \mathrm{mV} \mathrm{s}^{-1}$. Measurements were performed in chlorobenzene containing $0.1 \mathrm{M}$ $\mathrm{TBAPF}_{6}$ as the supporting electrolyte with a glassy carbon working electrode, a platinum counter electrode, and a silver pseudo-reference electrode. Corrected for ferrocene as an internal standard.

\section{Electrochemical characterization}

The one-electron oxidations and reductions of $\mathbf{C}_{\mathbf{6 0}}$-pyr.ZnP, $\mathbf{C}_{60}$-PPV1-pyr-ZnP, and $\mathbf{C}_{60}$-PPV3-pyr-ZnP and their $\mathbf{Z n P}$ and $\mathbf{C}_{60}$-PPV references were probed by cyclic voltammetry at room temperature in chlorobenzene (Table 1). For references, the first reversible oxidation of $\mathbf{Z n P}$ appears at $0.33 \mathrm{~V}$ whereas the first and second reversible reductions of $\mathbf{C}_{60}-\mathbf{p y r}, \mathbf{C}_{60}-\mathbf{P P V 1}-\mathbf{p y r}$ and $\mathbf{C}_{60}$-PPV3-pyr appear at $-1.24 /-1.63,-1.24 /-1.65$ and $-1.24 /-1.65 \mathrm{~V}\left(v s . \mathrm{Fc}^{+} / \mathrm{Fc}\right)$, respectively. In $\mathbf{C}_{60}$-pyr·ZnP, the oxidation of $\mathrm{ZnP}$ is shifted to $0.31 \mathrm{~V}\left(v s . \mathrm{Fc}^{+} / \mathrm{Fc}\right)$ and the first reduction of $\mathrm{C}_{60}$ occurs at $-1.21 \mathrm{~V}\left(v s . \mathrm{Fc}^{+} / \mathrm{Fc}\right)$. For $\mathbf{C}_{60}-\mathbf{P P V 1}-$ pyr.ZnP, and $\mathbf{C}_{60}$-PPV3-pyr.ZnP, the ZnP oxidation and $\mathrm{C}_{60}$ reduction are seen at 0.32 and $-1.25 \mathrm{~V}\left(v s . \mathrm{Fc}^{+} / \mathrm{Fc}\right)$, respectively, for both systems. Overall, the shifts are small with $10 \mathrm{mV}$. Nevertheless, all electron donor-acceptor ensembles show slightly easier oxidation as well as slightly easier reduction compared to their references. On careful examination of all of the redox data, we have concluded that the redox potentials in $\mathrm{C}_{60}$-oPPV.ZnPs are subject to minor shifts due to the axial coordination when compared to the corresponding references.

\section{Steady-state photophysical characterization}

In the absorption spectra of $\mathbf{C}_{60}$-PPV1-pyr and $\mathbf{C}_{60}$-PPV3-pyr, the characteristic absorptions of the individual $\mathrm{C}_{60}$ and $\mathrm{OPPV}$

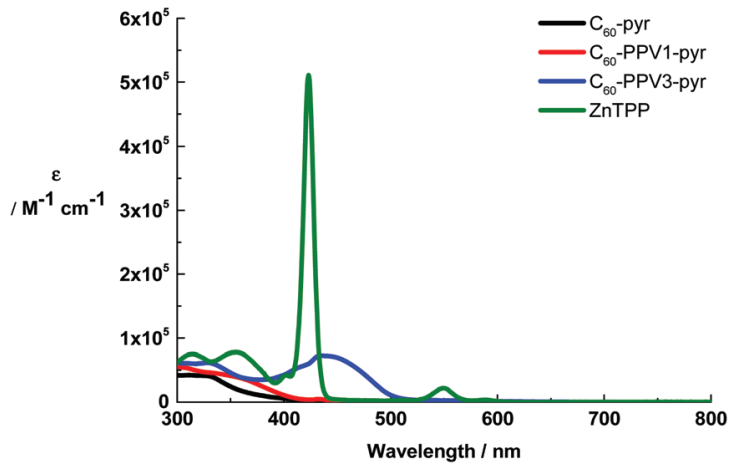

Fig. 1 Room temperature absorption spectra of $\mathrm{ZnP}$ (green), $\mathrm{C}_{60}-\mathrm{pyr}$ (black) $\mathrm{C}_{60}$-PPV1-pyr (red), $\mathrm{C}_{60}$-PPV3-pyr (blue) in chlorobenzene.

constituents are discernable (Fig. 1). In particular, $\mathrm{C}_{60}$ absorbs between 250 and $300 \mathrm{~nm}$, whereas the oPPVs exhibit broad maxima between 400 and $500 \mathrm{~nm}$ in $\mathbf{C}_{60}$-PPV1-pyr and $\mathbf{C}_{60^{-}}$ PPV3-pyr, respectively. It is important that the overall absorption characteristics depend on the length of the oPPVs; the red shift from 432 to $440 \mathrm{~nm}$ of the oPPV centered absorption in $\mathbf{C}_{60}$-PPV1-pyr and $\mathbf{C}_{60}$-PPV3-pyr as the overall oPPV length increase is consistent with the extended $\pi$-conjugation. Please note that the absorption of $\mathbf{C}_{\mathbf{6 0}}$-pyr, which is used to complement the series, is identical to that of the functionalized $\mathrm{C}_{60}$.

Turning to fluorescence spectroscopy, the oPPV and $\mathrm{C}_{60}$ constituents emit singlet excited state energy in different spectral regions of the spectrum. Upon excitation at $420 \mathrm{~nm}$, the fluorescence of oPPV is evident at $514 \mathrm{~nm}$ for $\mathbf{C}_{60}$-PPV3-pyr. Photoexcitation at $350 \mathrm{~nm}$ results, in stark contrast, in a weak emission due to $\mathrm{C}_{60}$ at $710 \mathrm{~nm} .^{50}$

In an attempt to coordinate zinc tetraphenylporphyrin (ZnP) to $\mathbf{C}_{60}$-pyr, $\mathbf{C}_{60}$-PPV1-pyr, and $\mathbf{C}_{60}$-PPV3-pyr several titration assays with a focus on the ground and the excited states were performed. In the ground state, the interactions of $\mathbf{C}_{60}$ pyr, $\mathbf{C}_{60}$-PPV1-pyr, and $\mathbf{C}_{60}$-PPV3-pyr with $\mathbf{Z n P}$ were followed by absorption spectroscopy in chlorobenzene. Absorption titrations were performed with, for example, $10^{-6} \mathrm{M}$ solutions of $\mathrm{ZnP}$ in the absence and presence of various concentrations of $\mathbf{C}_{60}$-pyr, $\mathbf{C}_{60}$-PPV1-pyr, and $\mathbf{C}_{60}$-PPV3-pyr. The concentrations of the latter were increased incrementally from 0 to $2.5 \times 10^{-5} \mathrm{M}$ and substantial changes were discernable in the absorption spectra. In particular, the original Soret band at $423 \mathrm{~nm}$ decreases in intensity. This decrease was accompanied by the formation of a new Soret band at $430 \mathrm{~nm}$ that implies the coordination of $\mathbf{Z n P}$ to $\mathbf{C}_{60}-\mathbf{p y r}, \mathbf{C}_{60}-\mathrm{PPV} 1-\mathrm{pyr}$, and $\mathbf{C}_{60}-\mathrm{PPV}$-pyr. Our hypothesis is corroborated by the development of an isosbestic point at $428 \mathrm{~nm}$. Binding constants of $1.2 \times 10^{4}$, $0.7 \times 10^{4}$, and $2.5 \times 10^{4} \mathrm{M}^{-1}$ were derived from the underlying concentration $v s$. absorption change relationships for $\mathbf{C}_{\mathbf{6 0}}-\mathbf{p y r}$, $\mathbf{C}_{60}$-PPV1-pyr, and $\mathbf{C}_{60}$-PPV3-pyr, respectively. In addition, Job's plot analyses were carried out. Here, the aforementioned spectral changes associated with $\mathbf{C}_{60}$-pyr·ZnP, $\mathbf{C}_{60}$-PPV1-pyr·ZnP, and $\mathbf{C}_{60}$-PPV3-pyr.ZnP at the Soret band maximum were used and plotted versus the mole fraction (Fig. S1†). Importantly, maxima were observed in all cases at mole fractions of 0.5 , 
which suggest 1:1 stoichiometries for $\mathbf{C}_{60}$-pyr-ZnP, $\mathbf{C}_{60}$-PPV1pyr-ZnP, and $\mathbf{C}_{60}$-PPV3-pyr.ZnP. Insights into excited-state interactions came from steady-state fluorescence measurements of ZnP in chlorobenzene solutions that were excited at either $420 \mathrm{~nm}$ or $556 \mathrm{~nm}$ to match the absorption of the ZnP Soret band or the $\mathrm{Q}$ band, respectively (Fig. 2). In particular, the intensity of the $\mathrm{ZnP}$-centered fluorescence, with maxima at 600 and $650 \mathrm{~nm}$ and quantum yield of 0.04, was found to depend on the concentrations of $\mathbf{C}_{60}-\mathbf{p y r}, \mathbf{C}_{60}-\mathbf{P P V 1}-\mathbf{p y r}$, and $\mathbf{C}_{60}$-PPV3-pyr, indicating the gradual transformation of $\mathbf{Z n P}$ into $\mathbf{C}_{60}$-pyr-ZnP, $\mathbf{C}_{60}$-PPV1-pyr-ZnP, and $\mathbf{C}_{60}$-PPV3-pyr-ZnP. Binding constants of $0.94 \times 10^{4}, 1.8 \times 10^{4}$, and $2.0 \times 10^{4} \mathrm{M}^{-1}$
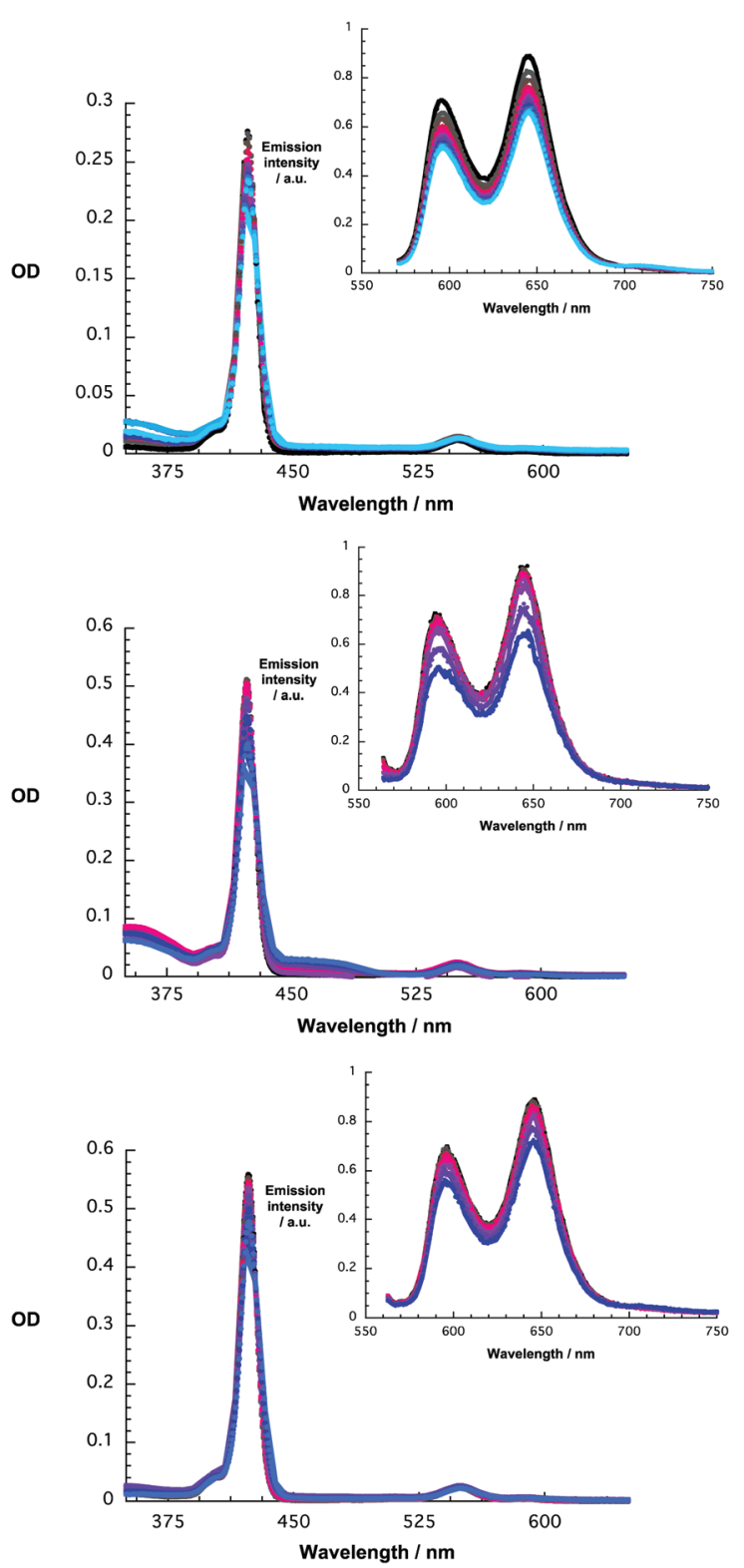

Fig. 2 Absorption spectra in chlorobenzene of $\mathrm{ZnP}\left(1.0 \times 10^{-6} \mathrm{M}\right)$ with variable concentrations of upper part: $\mathrm{C}_{60}$-PPV1-pyr $\left(0-2.5 \times 10^{-5} \mathrm{M}\right)$; middle part: $\mathrm{C}_{60}$-PPV3-pyr $\left(0-2.7 \times 10^{-5} \mathrm{M}\right)$ and lower part: $\mathrm{C}_{60}-$ pyr $\left(0-2.7 \times 10^{-5} \mathrm{M}\right)$. Insert: corresponding fluorescence spectra of each titration excited at $556 \mathrm{~nm}$. were obtained as $\log K_{\text {ass }}=(x . x)$ by nonlinear-least-square curve fitting of the ZnP fluorescence quenching at 595 and $645 \mathrm{~nm}$, for $\mathbf{C}_{60}$-pyr, $\mathbf{C}_{60}$-PPV1-pyr, and $\mathbf{C}_{60}$-PPV3-pyr, respectively. It is to be noted that these values are in excellent agreement with those derived from the absorption assays - vide supra.

\section{Time-resolved photophysical characterization}

The fluorescence titrations suggested a deactivation of the photoexcited electron donor-acceptor ensembles - $\mathbf{C}_{\mathbf{6 0}}$-pyrZnP, $\mathbf{C}_{60}$-PPV1-pyr-ZnP, and $\mathbf{C}_{60}$-PPV3-pyr-ZnP - via either intramolecular energy or electron transfer between the photoexcited $\mathrm{ZnP}$ and ground state $\mathrm{C}_{60}$. In order to shed light on the nature of the energy and/or electron transfer deactivation and the corresponding dynamics, we turned to femtosecond transient absorption experiments.

Representative differential absorption spectra taken, for example, upon the $420 \mathrm{~nm}$ excitation of $\mathbf{Z n P}$ in chlorobenzene solutions, are shown in Fig. S2. $\dagger$ Here, the differential absorption spectra recorded immediately after the laser pulse are characterized by bleaching of the ZnP Q band at $560 \mathrm{~nm}$ and the appearance of transients at $480 \mathrm{~nm}$ and between 580 and $750 \mathrm{~nm}$. These are spectral attributes of the $\mathbf{Z n P}$ singlet excited state $(2.04 \mathrm{eV})$. The latter decays slowly $\left(4.0 \times 10^{8} \mathrm{~s}^{-1}\right)$ in anisole to the energetically lower-lying $\mathbf{Z n P}$ triplet excited state $(1.53 \mathrm{eV})$ via intersystem crossing.

Now, considering the differential absorption spectra of $\mathbf{C}_{60^{-}}$ pyr-ZnP, $\mathbf{C}_{60}$-PPV1-pyr-ZnP, and $\mathbf{C}_{60}$-PPV3-pyr-ZnP we have probed the different ratios of $\mathbf{Z n P}$, on the one hand, and $\mathbf{C}_{\mathbf{6 0}^{-}}$ pyr, $\mathbf{C}_{60}$-PPV1-pyr, and $\mathbf{C}_{60}$-PPV3-pyr, on the other. Specifically, ratios of $1: 2,1: 5$ and $1: 10\left(\mathrm{c}(\mathrm{ZnP})=5 \times 10^{-5} \mathrm{M}\right)$ were used. To ensure selective excitation of $\mathbf{Z n P}$, excitations at 420 and $550 \mathrm{~nm}$ were selected for $\mathbf{C}_{60}-\mathbf{p y r} \cdot \mathbf{Z n P}, \mathbf{C}_{\mathbf{6 0}}$-PPV1-pyr·ZnP, and $\mathbf{C}_{60}$-PPV3-pyr-ZnP. The observation of an instantaneous growth of the broad absorption between 570 and $750 \mathrm{~nm}$ confirms the selective excitation of the $\mathrm{ZnP}$ in $\mathbf{C}_{60}$-pyr.ZnP, $\mathbf{C}_{60}$-PPV1pyr-ZnP, and $\mathbf{C}_{60}$-PPV3-pyr-ZnP (Fig. 3-5). However, within the first few picoseconds, these excited-state features give place to a transient absorption in the near infrared region that maximizes at $1020 \mathrm{~nm}$.

We have inferred the formation of the one-electron reduced $\mathrm{C}_{60}$ radical anion from these results. ${ }^{54}$ In the visible spectrum, the absorption of the one-electron oxidized $\mathrm{ZnP}$ radical cation emerges in the region 600-700 $\mathrm{nm}$. The latter is, however, to some extent masked by the much stronger $\mathrm{ZnP}$ triplet excited state as well as $\mathrm{C}_{60}$ triplet excited state features. ${ }^{55,56}$ Careful analyses of the absorption time profiles in the 600-700 nm and 900-1100 $\mathrm{nm}$ region enables the analysis of the chargetransfer rates of the $\mathrm{ZnP}$ radical cation and the $\mathrm{C}_{60}$ radical anion, respectively. The charge separation lifetimes in anisole are 25 ps for $\mathbf{C}_{60}-\mathbf{p y r} \cdot \mathbf{Z n P}, 2$ ps for $\mathbf{C}_{60}$-PPV1-pyr-ZnP, and 23 ps for $\mathbf{C}_{60}$-PPV3-pyr.ZnP.

In chlorobenzene, charge separation tends to be faster with 37 ps for $\mathbf{C}_{60}$-pyr.ZnP, 1 ps for $\mathbf{C}_{60}$-PPV1-pyr-ZnP and 15 ps for $\mathbf{C}_{60}$-PPV3-pyr.ZnP. ${ }^{57}$ The radical ion pair states are metastable in all cases and decay on the picosecond/nanosecond time scale. Lifetimes of 1189, 1585, and 320 ps in anisole and 991, 1076, 

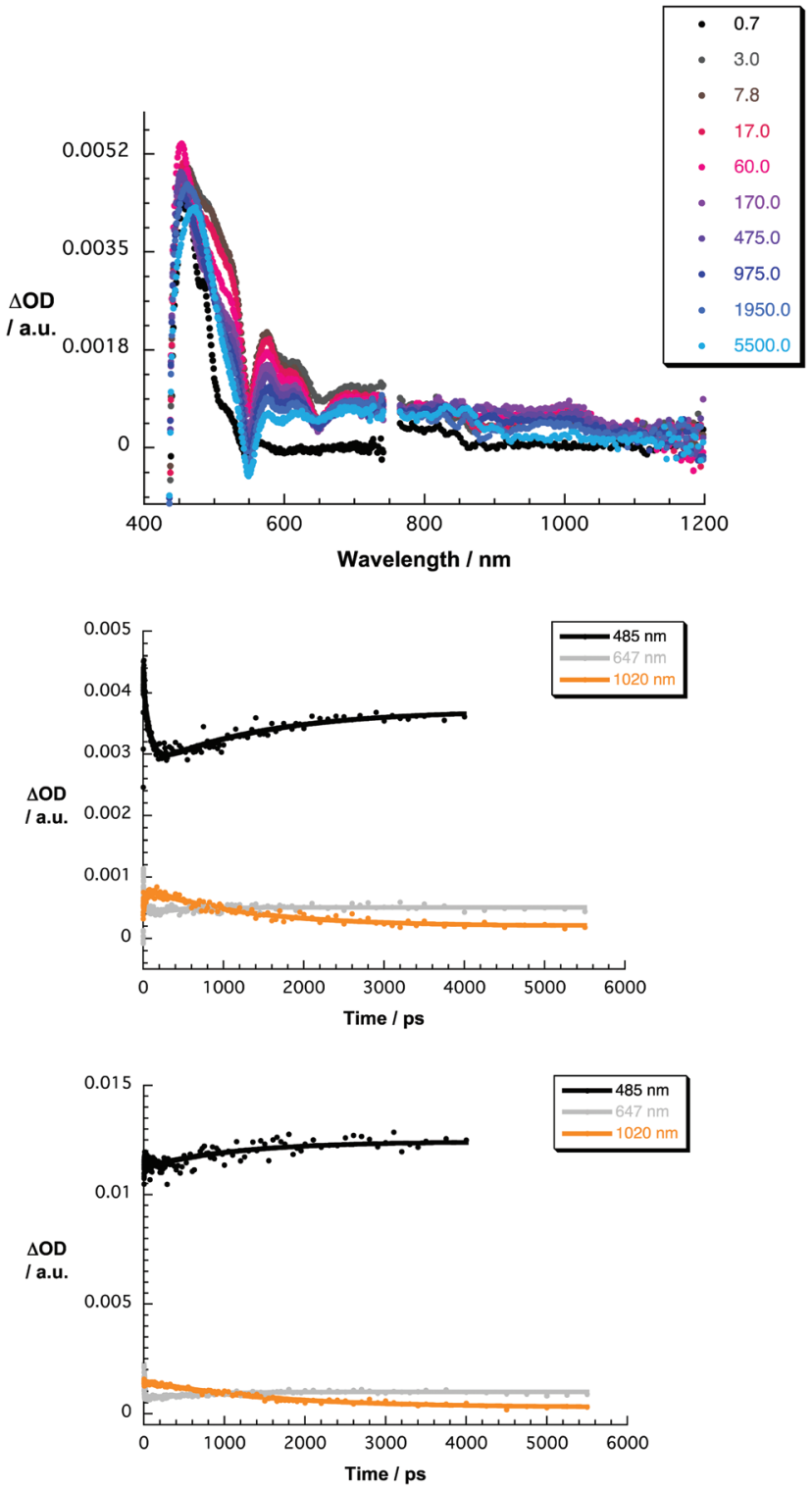

Fig. 3 Upper part - differential absorption spectra (visible and nearinfrared) obtained upon pump probe excitation ( $420 \mathrm{~nm}, 200 \mathrm{~nJ}$ ) of $\mathrm{C}_{60^{-}}$ PPV1-pyr.ZnP (in a 1 to 5 ratio) in chlorobenzene with several time delays between -0.7 and 5500 ps at room temperature - see legend for details. Central part - time-absorption profiles of the spectra shown above at 485, 647, and $1020 \mathrm{~nm}$ monitoring the charge separation and charge recombination. Lower part - time-absorption profiles of the spectra in anisole at 485, 647, and $1020 \mathrm{~nm}$ monitoring the charge separation and charge recombination.

and $250 \mathrm{ps}$ in chlorobenzene for $\mathbf{C}_{60}$-pyr.ZnP, $\mathbf{C}_{\mathbf{6 0}}$-PPV1-pyr·ZnP, and $\mathbf{C}_{60}$-PPV3-pyr.ZnP were determined, respectively (Table 2). ${ }^{58}$

The fact that charge recombination in $\mathbf{C}_{\mathbf{6 0}}$-PPV3-pyr.ZnP is faster than in $\mathbf{C}_{60}$-pyr-ZnP and $\mathbf{C}_{60}$-PPV1-pyr-ZnP despite the larger electron donor-acceptor separations is surprising. At first glance, it may be rationalized by invoking different total reorganization energies of the electron donor-acceptor ensembles due to larger electron donor-acceptor separations. To determine the reorganization energies for $\mathbf{C}_{\mathbf{6 0}}$-pyr.ZnP, $\mathbf{C}_{\mathbf{6 0}^{-}}$
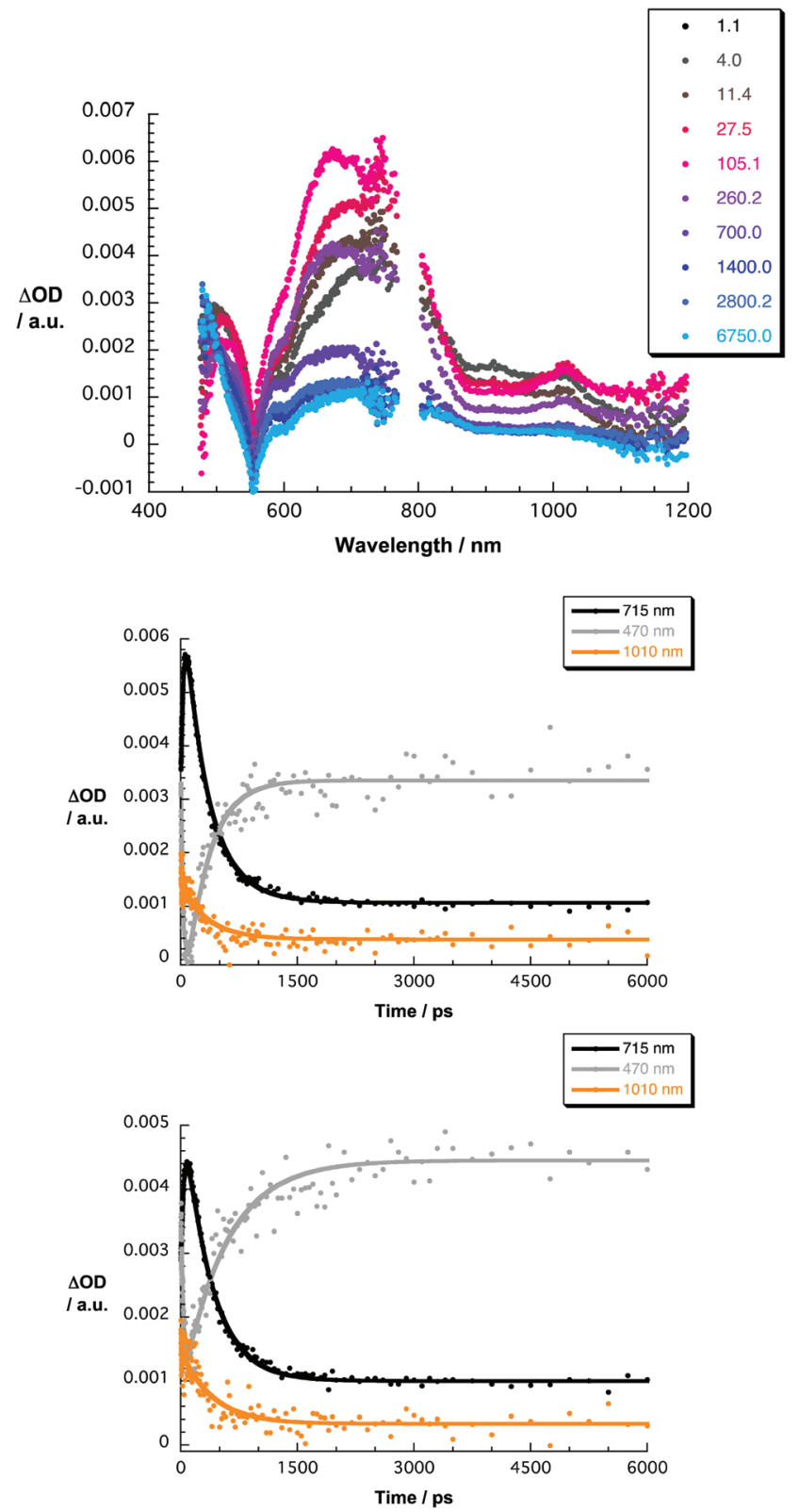

Fig. 4 Upper part - differential absorption spectra (visible and near-infrared) obtained upon pump probe excitation $(550 \mathrm{~nm}, 200 \mathrm{~nJ})$ of $\mathrm{C}_{60}$-PPV3pyr.ZnP (in a 1 to 5 ratio) in chlorobenzene with several time delays between 1.1 and 6750 ps at room temperature - see legend for details. Central part time-absorption profiles of the spectra shown above at 470, 715, and $1010 \mathrm{~nm}$ monitoring the charge separation and charge recombination. Lower part - time-absorption profiles of the spectra in anisole at 470, 715, and $1010 \mathrm{~nm}$ monitoring the charge separation and charge recombination.

PPV1-pyr-ZnP, and $\mathbf{C}_{60}$-PPV3-pyr·ZnP, the energy levels of the corresponding radical ion pair states were estimated using the continuum model for electron transfer (eqn 1), ${ }^{59}$

$$
\begin{aligned}
E_{\mathrm{IP}}= & E_{\mathrm{Ox}}-E_{\mathrm{red}}-\frac{1}{4 \pi \varepsilon_{0}} \frac{e^{2}}{\varepsilon_{\mathrm{S}} R_{\mathrm{DA}}}+\frac{e^{2}}{4 \pi \varepsilon_{0}}\left(\frac{1}{2 r_{\mathrm{D}}}+\frac{1}{2 r_{\mathrm{A}}}\right) \\
& \times\left(\frac{1}{\varepsilon_{\mathrm{S}}}-\frac{1}{\varepsilon_{\mathrm{S}}^{\prime}}\right)
\end{aligned}
$$



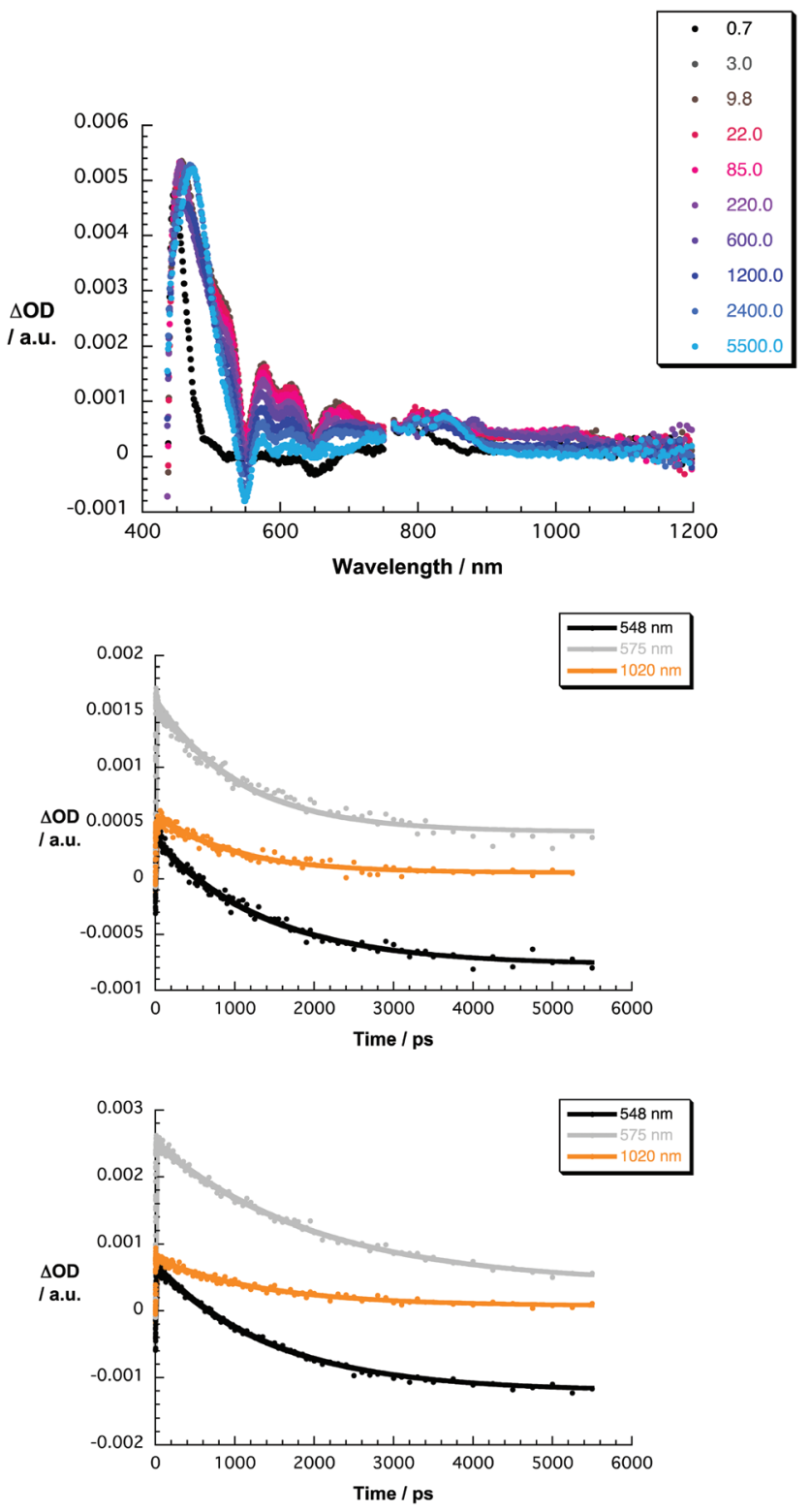

Fig. 5 Upper part - differential absorption spectra (visible) obtained upon pump probe excitation $\left(420 \mathrm{~nm}, 200 \mathrm{~nJ}\right.$ ) of $\mathrm{C}_{60}$-pyr· $\mathrm{ZnP}$ (in a 1 to 5 ratio) in chlorobenzene with several time delays between 0.7 and 5500 ps at room temperature - see legend for details. Central part time-absorption profiles of the spectra shown above at 548,575 , and $1020 \mathrm{~nm}$ monitoring the charge separation and charge recombination. Lower part - time-absorption profiles of the spectra in anisole at 548, 575, and $1020 \mathrm{~nm}$ monitoring the charge separation and charge recombination.

where $E_{\mathrm{ox}}$ and $E_{\text {red }}$ are the oxidation and reduction potentials, respectively, $e$ is the electronic charge, $\varepsilon_{0}$ is the dielectric constant of vacuum, $\varepsilon_{\mathrm{s}}$ is the static dielectric constant of the solvent, in which the rate constants are measured, $\varepsilon_{\mathrm{s}}{ }^{\prime}$ is the dielectric constant of the solvent, in which $E_{\text {ox }}$ and $E_{\text {red }}$ are measured, $R_{\mathrm{DA}}$ is the electron donor-acceptor center-to-center distance, and $r_{\mathrm{D}}$ and $r_{\mathrm{A}}$ are the spherical radii of the electron donor and acceptor, respectively. Notably, the $R_{\mathrm{DA}}$ are 10.6, 16.8, and $30 \AA$ for $\mathbf{C}_{60}$-pyr.ZnP, $\mathbf{C}_{60}$-PPV1-pyr.ZnP, and
$\mathrm{C}_{60}$-PPV3-pyr-ZnP, respectively. The spherical radii of the electron donor and acceptor are $r_{\mathrm{D}}=5.0 \AA$ and $r_{\mathrm{A}}=4.4 \AA$, respectively. $E_{\text {ox }}-E_{\text {red }}$ is $1.52,1.57$ and $1.57 \mathrm{~V}$ for $\mathbf{C}_{60}-$ pyr.ZnP, $\mathbf{C}_{60}$-PPV1pyr-ZnP, and $\mathrm{C}_{60}$-PPV3-pyr·ZnP, respectively.

$$
k_{\mathrm{ET}}=\sqrt{\frac{\pi}{\hbar \lambda k_{\mathrm{B}} T}}|V|^{2} \exp \left(-\frac{\left(\Delta G_{\mathrm{ET}}^{0}+\lambda\right)^{2}}{4 \lambda k_{\mathrm{B}} T}\right)
$$

The driving forces for charge-separation were evaluated by relating the aforementioned energy levels to those of the excited-state precursors, while those for the charge-recombination were taken from the radical ion pair states. Next, the electron transfer rate constants $\left(k_{\mathrm{ET}}\right)$, that is, charge-separation and charge-recombination, were treated as a function of driving forces $\left(-\Delta G_{\mathrm{ET}}^{0}\right)$, within the framework of the classical Marcus theory - eqn (2). ${ }^{30}$ In eqn (2), $k_{\mathrm{B}}$ is the Boltzmann constant, $V$ is the electronic coupling, and $\lambda$ is the reorganization energy. The classical Marcus theory helps in shedding light onto the total reorganization energies $\lambda$ (Fig. 6).

The fits of the Marcus parabola give a total reorganization energy of $0.91 \mathrm{eV}$ for $\mathbf{C}_{60}$-PPV3-pyr-ZnP, substantially larger than that derived for $\mathbf{C}_{60}-\mathbf{P P V 1}$-pyr·ZnP $(0.74 \mathrm{eV})$. $\mathbf{C}_{60}$-pyr-ZnP is an interesting case because its reorganization energy of $0.78 \mathrm{eV}$ is larger than that of $\mathbf{C}_{60} \mathbf{- P P V 1}-\mathbf{p y r} \cdot \mathbf{Z n P}$ but smaller than that of $\mathbf{C}_{60}$-PPV3-pyr.ZnP. A likely reason involves enhanced ground-state interactions in $\mathbf{C}_{60}$ - $\mathbf{p y r} \cdot \mathbf{Z n P}$ leading to electronic perturbation and, in turn, to a larger total reorganization energy. ${ }^{7}$ Implicit are rather large contributions from the internal reorganization energies as particularly evident in $\mathbf{C}_{60^{-}}$ pyr.ZnP. Considering electron donor-acceptor distances of 10.6, 16.8, $30 \AA$ in the non-covalent assemblies, we can also draw conclusions about the reorganization energies for $\mathrm{C}_{60^{-}}$ $\mathrm{ZnP}$ conjugates, in which the electron donor and the electron acceptor are covalently linked rather than non-covalently assembled (Fig. 6). To this end, we determined the distanceindependent values for $\mathrm{C}_{60}-\mathrm{OPPV}-\mathrm{ZnPs}$ of $0.72 \mathrm{eV}$ with oPPV trimers and pentamers, which correspond to electron donoracceptor distances of 25 and $39 \AA$, respectively. ${ }^{18}$

It is interesting to note the fact that the electronic couplings are 57,35 , and $10 \mathrm{~cm}^{-1}$ for $\mathbf{C}_{60}$-PPV1-pyr-ZnP, $\mathbf{C}_{60}$-PPV3pyr.ZnP, and $\mathbf{C}_{60}-\mathbf{p y r} \cdot \mathbf{Z n P}$, respectively. The difference between the latter one and the earlier two might be rationalized on the basis of different electron transfer mechanisms, that is, through-space versus through-bond.

To dissect the impact of the non-covalent assembly on the electron-transfer features we turned to the distance dependence of electron transfer by analyzing the charge separation in anisole and chlorobenzene. The damping factor $\beta$ was estimated by means of eqn (3), where $k_{0}$ is the pre-exponential factor, $\beta$ is the damping factor, and $R_{\mathrm{DA}}$ is the electron donoracceptor distance.

$$
k_{\mathrm{ET}}=k_{0} \exp \left(-\beta R_{\mathrm{DA}}\right)
$$

At first glance, and in stark contrast to the low damping factors found for $\mathrm{C}_{60}-\mathrm{OPPV}-\mathrm{ZnPs}$ with values as low as $0.03 \AA^{-1},{ }^{18}$ in $\mathrm{C}_{60}$-oPPV.ZnPs the value is $0.08 \AA^{-1}$ when plot- 
Table 2 Electron donor-acceptor center-to-center distances, charge separation and charge recombination dynamics, reorganization energies, electronic couplings, and damping factors

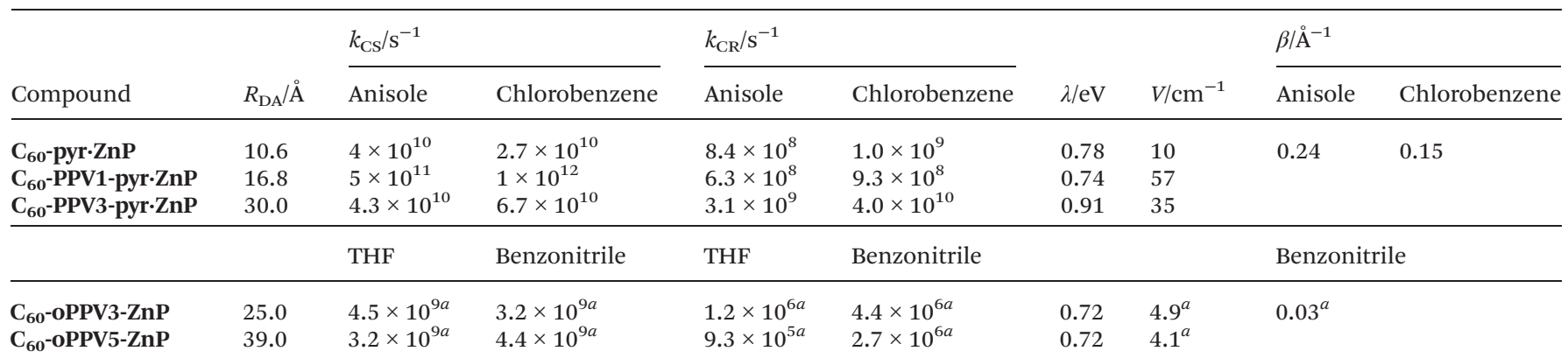

${ }^{a}$ G. de la Torre, F. Giacalone, J. L. Segura, N. Martín and D. M. Guldi, Chem. - Eur. J., 2005, 11, 1267-1280.
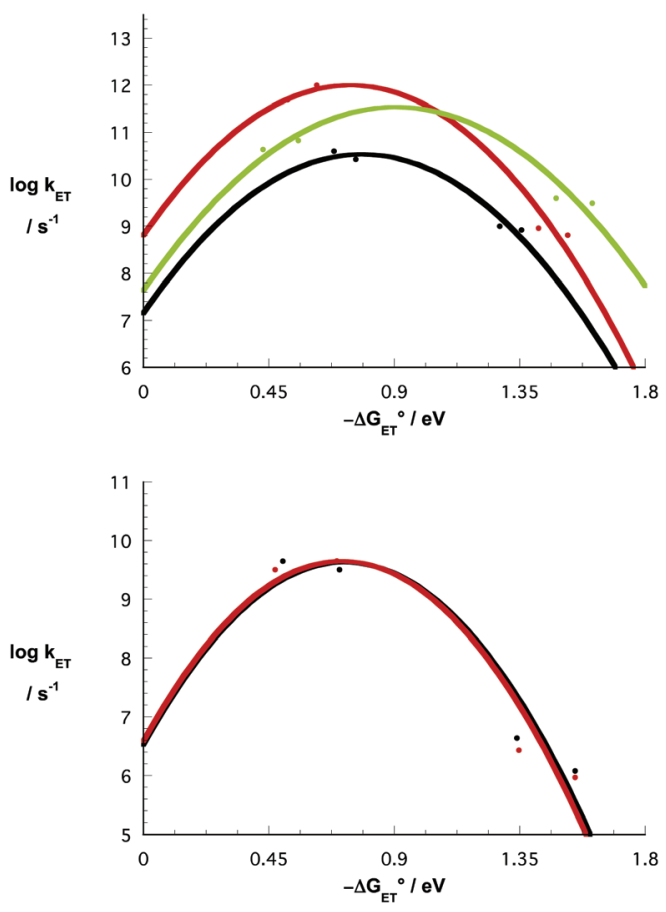

Fig. 6 Upper part - driving force $\left(-\Delta G_{E T}^{0}\right)$ dependences of the rate constants for charge separation and charge recombination for $\mathrm{C}_{60^{-}}$ PPV1-pyr.ZnP (red), $\mathrm{C}_{60}-\mathrm{PPV} 3-\mathrm{pyr} \cdot \mathrm{ZnP}$ (green), and $\mathrm{C}_{60}$-pyr.ZnP (black). Lower part - driving force $\left(-\Delta G_{\mathrm{ET}}^{0}\right)$ dependences of the rate constants for charge separation and charge recombination for $\mathrm{C}_{60}-\mathrm{PPPV}_{3}-\mathrm{ZnP}$ (black) and $\mathrm{C}_{60}-\mathrm{OPPV}_{5}-\mathrm{ZnP}$ (red).

ting the maximum rate constant (Fig. 7). The sole difference between $\mathrm{C}_{60}$-oPPV-ZnPs and $\mathrm{C}_{60}$-oPPV-ZnPs is the linkage, that is, either covalently via the peripheral phenyl groups or non-covalently via the central zinc. A closer look at the local electron affinity maps for $\mathbf{C}_{60}$-pyr·ZnP, $\mathbf{C}_{60}$-PPV1-pyr·ZnP, and $\mathbf{C}_{60}$-PPV3pyr-ZnP versus $\mathbf{C}_{60}$-oPPV3-ZnP and $\mathbf{C}_{60}$-oPPV5-ZnP corroborates a fairly homogeneous pathway for electrons from the photoexcited/electron donating $\mathrm{ZnP}$ to the electron accepting $\mathrm{C}_{60}$ in the latter. In the earlier, the same homogeneity prevails but comes to a sudden stop at the pyridinic nitrogen. In other words, nitrogen emerges as a bottleneck in the electron

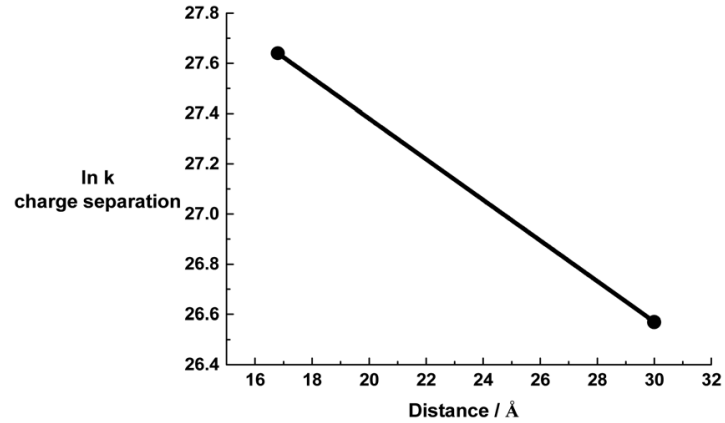

Fig. 7 Distance dependence of electron-transfer rate constants in $\mathbf{C}_{60}$ PPV1-pyr-ZnP and $\mathrm{C}_{60}-\mathrm{PPV} 3-$ pyr-ZnP in nitrogen-saturated anisole (black) and chlorobenzene (red) at room temperature.

transport through $\mathbf{C}_{60}-\mathbf{p y r} \cdot \mathbf{Z n P}, \mathbf{C}_{60}-\mathbf{P P V 1}$-pyr·ZnP, and $\mathbf{C}_{60^{-}}$ PPV3-pyr.ZnP and, in turn, increases the damping factor.

A final consideration is associated with the local electronic affinity maps, which clearly reveal distributions of low local electron affinity at the zinc spilling over to the pyridinic nitrogen for coordinative compounds (Fig. 8). As a matter of fact, the delocalization of the $\mathrm{ZnP}$ radical cation throughout the porphyrin including the central zinc assists in rationalizing the fairly large reorganization energies in $\mathbf{C}_{60}$-pyr.ZnP, $\mathbf{C}_{60^{-}}$ PPV1-pyr-ZnP, and $\mathbf{C}_{60}$-PPV3-pyr-ZnP and, more importantly, its distance dependence.

In addition, the lowest-lying singlet charge-transfer state of $\mathbf{C}_{60}$-pyr-ZnP shows significant deviations from the ground state geometry as it moves the charged moieties closer to each other. The axial $\mathrm{Zn}-\mathrm{N}$ bond is bent approximately $2^{\circ}$ towards the electron accepting $\mathrm{C}_{60}$ and the pyridine ring assumes a distinct boat conformation with $9^{\circ}$ and $5^{\circ}$ deviations from planarity (Fig. 9). These distortions result in the charged $\mathrm{C}_{60}$ moving approximately $1 \AA$ closer to one of the twisted phenyl substituents, allowing stabilization by $\mathrm{CH}$... C hydrogen bonding. The latter turns out to be quite favorable in this case because of the negative charge on $\mathrm{C}_{60}$. The charge-transfer nature of this state is demonstrated unambiguously by the calculated (AM1CI) molecular electrostatic potential on the 0.001 a.u. isodensity surface. It corresponds approximately to the van der Waals surface shown in Fig. 9. Regarding $\mathbf{C}_{60}-\mathbf{P P V 1}-\mathbf{p y r} \cdot \mathbf{Z n P}$ and 

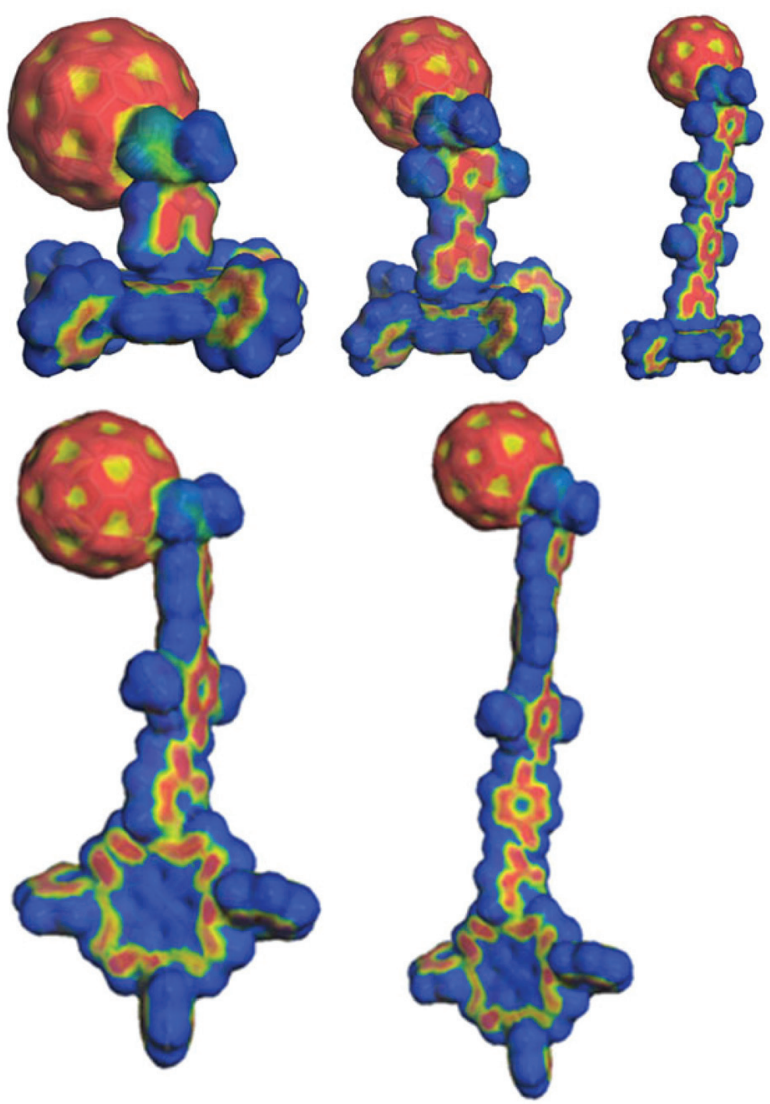

Fig. 8 Upper part - EA $A_{\llcorner}$mapped from -80.0 (blue) to $-30.0 \mathrm{kcal} \mathrm{mol}^{-1}$ (red) onto the electronic density isosurfaces $\left(0.03 \mathrm{e}^{-} \AA^{-3}\right)$ of $\mathrm{C}_{60}$-pyr.ZnP, $\mathrm{C}_{60}-\mathrm{PPV1}$-pyr$\cdot \mathrm{ZnP}$, and $\mathrm{C}_{60}-\mathrm{PPV} 3-\mathrm{pyr} \cdot \mathrm{ZnP}$. Lower part - EA $\mathrm{A}_{\mathrm{L}}$ mapped from -80.0 (blue) to $-30.0 \mathrm{kcal} \mathrm{mol}^{-1}$ (red) onto the electronic density isosurfaces $\left(0.03 \mathrm{e}^{-} \AA^{-3}\right)$ of $\mathrm{C}_{60}-\mathrm{OPPV}_{3}-\mathrm{ZnP}$ and $\mathrm{C}_{60}-\mathrm{OPPV}_{5}-\mathrm{ZnP}$.
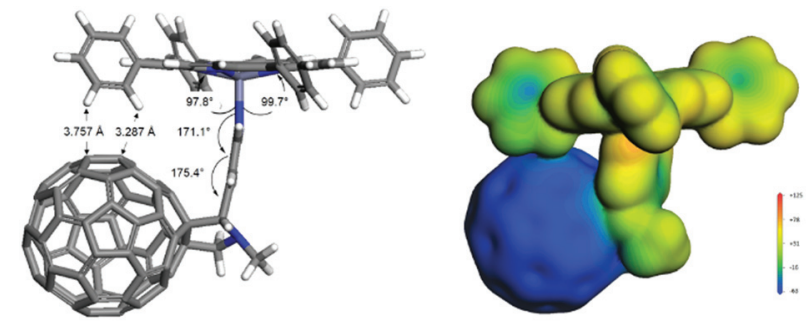

Fig. 9 Left part - geometry of the lowest-lying singlet charge-transfer state of $\mathrm{C}_{60}$-pyr.ZnP. Right part - electrostatic potential on the 0.001 a.u. isodensity surface calculated by AM1-Cl.

$\mathbf{C}_{60}$-PPV3-pyr.ZnP no particular CT states were calculable due to the rather large distances between electron donors and acceptors.

\section{Conclusions}

The integration of $\mathrm{ZnP}$ into short and long oPPVs bearing $\mathrm{C}_{60}$, namely $\mathbf{C}_{60}$-PPV1-pyr and $\mathbf{C}_{60}$-PPV3-pyr is accomplished via coordination to the pyridyl groups. As such, the corresponding
$\mathbf{C}_{60}$-PPV1-pyr-ZnP and $\mathbf{C}_{60}$-PPV3-pyr.ZnP are fully characterized by complementary spectroscopic means, but fail to give rise to appreciable electronic interactions in the ground state. In the excited state, electronic interactions between photoactive $\mathrm{ZnP}$ and $\mathbf{C}_{60}$-PPV1-pyr and $\mathbf{C}_{60}$-PPV3-pyr are inferred from fluorescence spectroscopy. By means of transient absorption measurements we have confirmed that the excited state interactions lead to the formation of radical ion pair states, that is, the one electron oxidized $\mathrm{ZnP}$ radical cation and the one electron reduced $\mathrm{C}_{60}$ radical anion. In both instances the radical ion pair states are metastable with, however, $\mathbf{C}_{60}$-PPV3-pyr·ZnP showing a faster charge recombination than $\mathbf{C}_{\mathbf{6 0}}$-PPV1-pyr·ZnP despite the larger electron donor-acceptor separation. This rather surprising result stems from a distinct distance dependence found for $\mathbf{C}_{\mathbf{6 0}}$-PPV1-pyr·ZnP and $\mathbf{C}_{\mathbf{6 0}}$-PPV3-pyr·ZnP with electron donor-acceptor distances of 16.8 and $30 \AA$ and reorganization energies of 0.74 and $0.91 \mathrm{eV}$, respectively. In contrast, linking the $\mathrm{ZnP}$ covalently to $\mathrm{C}_{60}$-oPPVs at, for example, electron donor-acceptor distances between 24.9 and $38.7 \AA$ leads to invariant reorganization energies of around $0.72 \mathrm{eV}$. This difference goes hand in hand with changes in the damping factor with values as low as $0.03 \AA^{-1}$ for the covalently linked conjugates and as high as $0.08 \AA^{-1}$ for $\mathbf{C}_{60^{-}}$ PPV1-pyr-ZnP and $\mathbf{C}_{60}$-PPV3-pyr-ZnP. Insights into the noted differences came from molecular modeling, which discloses that the fairly homogeneous pathway for electrons from the electron-donating $\mathrm{ZnP}$ to the electron-accepting $\mathrm{C}_{60}$ is suddenly disrupted at the pyridinic nitrogen. In light of the aforementioned observations, the ability to control electron transfer rates by modulating the reorganization energy in non-covalent ensembles opens new perspectives for the design and preparation of new architectures potentially efficient for energy applications.

\section{Acknowledgements}

Financial support from the European Commission (FP7REGPOT-2008-1, Project BIOSOLENUTI No 229927) is greatly acknowledged. This research was also co-financed by the European Union (European Social Fund-ESF) and Greek national funds through the Operational Program "Education and Lifelong Learning" of the National Strategic Reference Framework (NSRF)-Research Funding Program: Heraklitos II. Finally, the Special Research account of the University of Crete is also acknowledged. Partial financial support from the Greek General Secretariat for Research and Technology and the European Commission, through the European Fund for Regional Development, NSRF 2007-2013 action "Development of Research Centers - КРНПI $\Sigma$ ”, project 447963 "New Multifunctional Nanostructured Materials and Devices POLYNANO" to NT is acknowledged. This work was supported by MICINN and MEC, Spain (CTQ-2011-24187/BQU and PIB2010US-00652). J. T. Margraf was supported by a Beilstein Foundation scholarship. S. Kuhri and C. Schubert were supported by EAM, and C. Stangel by Heraklitos II. 


\section{Notes and references}

1 M. R. Wasielewski, Chem. Rev., 1992, 92, 435-461.

2 R. E. Blankenship, Molecular Mechanisms of Photosynthesis, Blackwell Science, Oxford, U.K., 2002.

3 D. Gust, T. A. Moore and A. L. Moore, Acc. Chem. Res., 1993, 26, 198-205.

4 H. B. Gray and J. R. Winkler, Annu. Rev. Biochem., 1996, 65, 537-561.

5 M. Grätzel, J. Photochem. Photobiol., C, 2003, 4, 145-153.

6 T. Nakanishi, Supramolecular Soft Matter, Applications in Materials and Organic Electronics, John Wiley \& Sons, New Jersey, 2011.

7 D. M. Guldi, Chem. Soc. Rev., 2002, 31, 22-36.

8 F. D'Souza, Handbook of Carbon Nanomaterials, Synthesis and Supramolecular Systems, World Scientific Publishing Co. Pte. Ltd, Singapore, 2011.

9 H. Imahori, Y. Mori and Y. Matano, J. Photochem. Photobiol., C, 2003, 4, 51-83.

10 V. Balzani, A. Credi and M. Venturi, ChemSusChem, 2008, 1, 26-58.

11 M. E. El-Khouly, O. Ito, P. M. Smith and F. D'Souza, J. Photochem. Photobiol., C, 2004, 5, 79-104.

12 K. Kadish, K. M. Smith and R. Guilard, The porphyrin handbook, Academic Press, San Diego, London, 2000.

13 H. Imahori, H. Yamada, D. M. Guldi, Y. Endo, A. Shimomura, S. Kundu, K. Yamada, T. Okada, Y. Sakata and S. Fukuzumi, Angew. Chem., Int. Ed., 2002, 41, 2344-2347.

14 S. Fukuzumi, K. Ohkubo, H. Imahori and D. M. Guldi, Chem. - Eur. J., 2003, 9, 1585-1593.

15 J.-F. N. F. Langa, Fullerenes: Principles and Applications, Nanoscience and Nanotechnology Series, The Royal Society of Chemistry, Cambridge, U.K, 2007.

16 N. M. D. M. Guldi, Fullerenes: From Synthesis to Optoelectronic Applications, Kluwer Academic, Dordrecht, 2002.

17 F. Giacalone, J. L. Segura, N. Martín, J. Ramey and D. M. Guldi, Chem. - Eur. J., 2005, 11, 4819-4834.

18 G. de la Torre, F. Giacalone, J. L. Segura, N. Martín and D. M. Guldi, Chem. - Eur. J., 2005, 11, 1267-1280.

19 G. Accorsi, N. Armaroli, J.-F. Eckert and J.-F. Nierengarten, Tetrahedron Lett., 2002, 43, 65-68.

20 J. L. Segura, R. Gomez, N. Martin, C. Luo, A. Swartz and D. M. Guldi, Chem. Commun., 2001, 707-708.

21 D. M. Guldi, A. Swartz, C. Luo, R. Gómez, J. L. Segura and N. Martín, J. Am. Chem. Soc., 2002, 124, 10875-10886.

22 F. Langa, M. a. J. Gómez-Escalonilla, E. Díez-Barra, J. n. C. García-Martínez, A. de la Hoz, J. Rodríguez-López, A. González-Cortés and V. López-Arza, Tetrahedron Lett., 2001, 42, 3435-3438.

23 J.-F. Nierengarten, N. Armaroli, G. Accorsi, Y. Rio and J.-F. Eckert, Chem. - Eur. J., 2003, 9, 36-41.

24 T. Nhu, Y. Hoang, D. Pociecha, M. Salamonczyk, E. Gorecka and R. Deschenaux, Soft Matter, 2011, 7, 4948-4953.

25 T. M. Figueira-Duarte, Y. Rio, A. Listorti, B. Delavaux-Nicot, M. Holler, F. Marchioni, P. Ceroni, N. Armaroli and J.-F. Nierengarten, New J. Chem., 2008, 32, 54-64.
26 J. Santos, B. M. Illescas, M. Wielopolski, A. M. G. Silva, A. C. Tomé, D. M. Guldi and N. Martín, Tetrahedron, 2008, 64, 11404-11408.

27 F. Giacalone, J. L. Segura, N. Martín and D. M. Guldi, J. Am. Chem. Soc., 2004, 126, 5340-5341.

28 D. M. Guldi, B. M. Illescas, C. M. Atienza, M. Wielopolski and N. Martin, Chem. Soc. Rev., 2009, 38, 1587-1597.

29 N. Armaroli, F. Barigelletti, P. Ceroni, J.-F. Eckert, J.-F. Nicoud and J.-F. Nierengarten, Chem. Commun., 2000, 599-600.

30 R. A. Marcus, J. Chem. Phys., 1956, 24, 966-978.

31 R. A. Marcus, J. Chem. Phys., 1965, 43, 679-701.

32 E. Peeters, P. A. van Hal, J. Knol, C. J. Brabec, N. S. Sariciftci, J. C. Hummelen and R. A. J. Janssen, J. Phys. Chem. B, 2000, 104, 10174-10190.

33 J.-F. Eckert, J.-F. Nicoud, J.-F. Nierengarten, S.-G. Liu, L. Echegoyen, F. Barigelletti, N. Armaroli, L. Ouali, V. Krasnikov and G. Hadziioannou, J. Am. Chem. Soc., 2000, 122, 7467-7479.

34 N. Armaroli, G. Accorsi, J.-P. Gisselbrecht, M. Gross, V. Krasnikov, D. Tsamouras, G. Hadziioannou, M. J. Gomez-Escalonilla, F. Langa, J.-F. Eckert and J.-F. Nierengarten, J. Mater. Chem., 2002, 12, 2077-2087.

35 A. M. Ramos, S. C. J. Meskers, P. A. van Hal, J. Knol, J. C. Hummelen and R. A. J. Janssen, J. Phys. Chem. A, 2003, 107, 9269-9283.

36 A. Gégout, J.-F. Nierengarten, B. Delavaux-Nicot, C. Duhayon, A. Saquet, A. Listorti, A. Belbakra, C. Chiorboli and N. Armaroli, Chem. - Eur. J., 2009, 15, 8825-8833.

37 A. Gegout, J. L. Delgado, J.-F. Nierengarten, B. DelavauxNicot, A. Listorti, C. Chiorboli, A. Belbakra and N. Armaroli, New J. Chem., 2009, 33, 2174-2182.

38 D. M. Guldi and V. Sgobba, Chem. Commun., 2011, 47, 606610.

39 T. Hasobe, Phys. Chem. Chem. Phys., 2012, 14, 15975-15987. 40 T. Umeyama and H. Imahori, J. Phys. Chem. C, 2012, 117, 3195-3209.

41 J.-M. Lehn, Proc. Natl. Acad. Sci. U. S. A., 2002, 99, 47634768.

42 J. F. Stoddart and H.-R. Tseng, Proc. Natl. Acad. Sci. U. S. A., 2002, 99, 4797-4800.

43 W. L. F. Armarego and C. L. L. Chai, Purification of Laboratory Chemicals, Elsevier Inc., Oxford, 6th edn, 2009.

44 P. Rothemund and A. R. Menotti, J. Am. Chem. Soc., 1948, 70, 1808-1812.

45 B. Ehresmann, B. Martin, A. H. C. Horn and T. Clark, J. Mol. Model, 2003, 9, 342-347.

46 M. J. S. Dewar, E. G. Zoebisch, E. F. Healy and J. J. P. Stewart, J. Am. Chem. Soc., 1985, 107, 3902-3909.

47 T. T. Clark and M. Hennemann, EMPIRE'12, 2011.

48 B. Ehresmann, B. Martin, A. C. Horn and T. Clark, J. Mol. Model, 2003, 9, 342-347.

49 T. Clark, J. Mol. Model, 2010, 16, 1231-1238.

50 M. Prato and M. Maggini, Acc. Chem. Res., 1998, 31, 519-526. 51 J. Boutagy and R. Thomas, Chem. Rev., 1974, 74, 87-99.

52 P. Shao, Z. Li, J. Luo, H. Wang and J. Qin, Synth. Commun., 2005, 35, 49-53. 
53 B. Wang and M. R. Wasielewski, J. Am. Chem. Soc., 1997, 119, 12-21.

54 D. M. Guldi and M. Prato, Acc. Chem. Res., 2000, 33, 695703.

55 V. A. Walters, J. C. de Paula, B. Jackson, C. Nutaitis, K. Hall, J. Lind, K. Cardozo, K. Chandran, D. Raible and C. M. Phillips, J. Phys. Chem., 1995, 99, 1166-1171.

56 J. Fajer, D. C. Borg, A. Forman, D. Dolphin and R. H. Felton, J. Am. Chem. Soc., 1970, 92, 3451-3459.

57 In addition, we note a second, slower electron transfer process in $\mathbf{C}_{60}$-PPV1-pyr.ZnP, which evolves from a $\mathrm{C}_{60}$ singlet excited state generated by means of an initial excited state energy transfer.

58 Importantly, the charge recombination reinstates the ground state rather than the triplet excited state of, for example, the ZnP. This pathway was confirmed in singlet oxygen measurements as a reflection of the $\mathrm{ZnP}$ and $\mathrm{C}_{60}$ triplet excited state quantum yields. In titration experiments, where an access of $\operatorname{ZnP}(10: 1$ and $30: 1)$ was present, a $\mathrm{C}_{60}$ concentration dependent and gradual decrease of the singlet oxygen emission was noted.

59 A. Weller, Z. Phys. Chem., Neue Folge, 1982, 133, 93-98. 